\title{
Article \\ Hybrid Chaotic Discrete Bat Algorithm with Variable Neighborhood Search for Vehicle Routing Problem in Complex Supply Chain
}

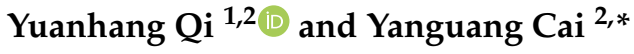 \\ 1 School of Computer Science, University of Electronic Science and Technology of China, Zhongshan Institute, \\ Zhongshan 528402, China; qiyuanhang@zsc.edu.cn \\ 2 School of Automation, Guangdong University of Technology, Guangzhou 510006, China \\ * Correspondence: caiyg99@163.com
}

Citation: Qi, Y.; Cai, Y. Hybrid Chaotic Discrete Bat Algorithm with Variable Neighborhood Search for Vehicle Routing Problem in Complex Supply Chain. Appl. Sci. 2021, 11, 10101. https://doi.org/10.3390/ app112110101

Academic Editors: Jarosław Wikarek and Paola Pellegrini

Received: 15 August 2021

Accepted: 25 October 2021

Published: 28 October 202

Publisher's Note: MDPI stays neutral with regard to jurisdictional claims in published maps and institutional affiliations.

Copyright: (C) 2021 by the authors Licensee MDPI, Basel, Switzerland. This article is an open access article distributed under the terms and conditions of the Creative Commons Attribution (CC BY) license (https:// creativecommons.org/licenses/by/ $4.0 /)$

\begin{abstract}
Driven by the supply chain, suppliers, manufacturers and warehouses are working more closely together for improving service quality. However, tremendous cost may incur in the supply chain if transportation is not planned properly and efficiently, which frustrates enterprises in the intense market. In this paper, we present a model of vehicle routing problem in complex supply chain (VRPCSC) and propose an intelligent algorithm called hybrid chaotic discrete bat algorithm with variable neighborhood search for minimizing the purchase cost of materials, processing cost, and delivery cost along the path from suppliers, to manufacturers and warehouses in the vehicle routing problem. Based on the principles of bat algorithm, a discrete chaotic initialization strategy (DCIS) and a variable neighborhood search (VNS) are adopted to enhance the convergence capacity. Finally, two sets of experiments are conducted, which show that the proposed algorithm can solve the VRPCSC effectively.
\end{abstract}

Keywords: supply chain; transportation systems; artificial intelligence; intelligent algorithm; vehicle routing; bat algorithm

\section{Introduction}

With the development of big data, artificial intelligence, and high-performance computing techniques, the supply chain is reaching a new level. Based on these, more and more complex segments can be considered in the supply chain management to create lower costs and greater benefits. Nowadays, suppliers, manufacturers, and warehouses are working more closely together, driven by the supply chain, and they cooperate with each other to gain a share of the market. The enterprises have to effectively manage the transportation of supply chain, so as to meet the current stringent market demand at the lowest cost [1]. How to improve the efficiency of the supply chain has become a hot topic in supply chain management.

Supply chain cost is mainly composed of material costs, labor cost, transportation cost, equipment cost, and other variable cost [2]. Among them, transportation cost is an important part of supply chain cost. Research of Apte U.M indicated that $30 \%$ of product cost is used for vehicle routing [3]. A reasonable vehicle routing in the supply chain plays an important role in reducing supply chain costs [4]. Therefore, reducing transportation cost in the supply chain is one of the effective ways to improve the efficiency of the supply chain [5].

Cross Docking (CD) is one of the effective transportation strategies for supply chain management, which involves the transportation and store management of products: products are collected and transported to cross docks by inbound vehicles, and after integrating and sorting the products, the products are loaded and transported to customers by inbound vehicles [6]. CD can effectively improve the flowability of the products while reducing 
the storage cost and the storage space [7]. Therefore, since CD was first proposed by Rohrer [8] in 1995, it has attracted significant research attention, and has also been successfully applied in the supply chain. Yu et al. [9] designed nine heuristic algorithms with different strategies to solve $\mathrm{CD}$, whose objective is to minimize total operation time or to maximize the throughput of cross docks. The actual transportation capacity of cross docks is limited, which may cause product transportation delays. Therefore, considering the penalty costs for all the unfulfilled products, Lim et al. [10] propose a over-constrained vehicle routing problem with a time window, operational time, and capacity constraint for $\mathrm{CD}$. Some special industries have their own special requirements for transportation and storage. For example, the food industry has strict cooling requirements and is highly intolerant of intermediate storages inside the terminal. In addressing this, Boysen [11] proposes a model for truck scheduling at zero-inventory cross docking terminals for the food industry. Considering multiple products and different product prices supplied by different suppliers, Ahmadizar et al. [12] established a model whose objective is to minimize the purchasing, transportation, and holding costs. Reverse logistics is an important part of modern logistics. Zuluaga et al. [13] analyzed the process of reverse logistics and proposed a reverse cross docking model. However, in the current research on $C D$, most researchers only focus on the integrated distribution process without considering the impact of manufacturers' processing.

The manufacturing process, as an important factor, is necessary to consider in supply chain management. Therefore, some supply chain researches considered the production, inventory, and transportation scheduling in the supply chain, which is called the production routing problem (PRP). Based on a supply chain with a single product, multiple factories, and multiple customers, Liu [14] establishes a model for the integrated PRP which considers the production capacity, inventory capacity, material supply contract, inventory holding cost, and production cost. Qiu et al. [15] propose a model for a pollution production routing problem (PPRP) with carbon cap-and-trade whose objective is to reduce emission levels of carbon dioxide. Based on the PPRP, considering the time window constraint, aiming to minimize fuel costs and operating costs, Kumar et al. [16] propose a multiobjective PPRP model with a time window. Considering the impact of carbon emissions in the transportation process and integrating the production, inventory, transportation, and distribution, Darvish et al. [17] established a three-echelon supply chain vehicle scheduling model and adopted accurate algorithms to solve it. However, the above papers only consider the transportation after the production process, and does not consider the transportation before the production process, that is, the process of suppliers providing materials to the factory. In addition, complex products in real life are often manufactured from multiple materials, and different materials may be provided by different suppliers, even different suppliers supply different materials with different costs.

Base on above, this paper takes into consideration the fact that complex products are made from multiple materials on the basis of the three-echelon supply chain, taking into account factors such as maximum material supply quantity, vehicle capacity, material costs, processing cost and distribution costs, and proposes a model of the vehicle routing problem in complex supply chain (VRPCSC) with an aim to minimize the purchasing, production, and transportation costs. The VRPCSC satisfies the transport constraints, which is an NP-hard problem. More and more scholars have been applying meta heuristic algorithms to deal with this kind of problem [18,19]. Based on our previous studies [20,21], the Discrete Bat Algorithm (DBA) can solve routing problems effectively. Because there are two-part routings in the VRPCSC (one is between supplier and manufacturers, the other is between manufacturers and the warehouse), this paper proposes a hybrid discrete bat algorithm optimized by the local search. In addition, this paper adopts a discrete chaotic initialization strategy (DCIS) [22] to strengthen the prophase convergence rate and overall convergence effect of the algorithm.

The contributions of this paper are as follows: (1) Based on a three-echelon supply chain included suppliers, manufacturers, and warehouses, considering the fact that com- 
plex products with multiple materials are process by-manufacturers, a model of VRPCSC is proposed; (2) For the complex supply chain model, a hybrid chaotic discrete bat algorithm with a variable neighborhood search (denoded as HCDBAVNS) is presented to solve it.

The remainder of this paper is organized as follows: Section 2 presents the model of VRPCSC to describe the vehicle routing among suppliers, manufacturers, and warehouses. Section 3 proposes the HCDBAVNS algorithm and describes the implementation in detail. 20 test instances are chosen as the study case to demonstrate the proposed algorithm and its optimization strategies in Section 4. Some conclusions and future work are finally addressed in Section 5.

\section{Problem Model}

In this subsection, VRPCSC is described in detail. Based on the description, the mathematical model of VRPCSC is proposed.

\subsection{Problem Description}

In VRPCSC, the warehouses purchase materials from suppliers according to their respective demand for products. The suppliers deliver materials to manufacturers by vehicle. The manufacturers make materials into products, and then deliver the products to the warehouses by vehicle. The VRPCSC distribution process is shown in Figure 1, which consists of four parts, i.e., material procurement, material delivery, material processing, and product delivery. VRPCSC is based on the perspective of third-party logistics companies. Third-party logistics companies choose different suppliers and manufacturers to satisfy the demands of clients(warehouses), with the goal being to minimize the total costs. This study employs a parametric approach for modeling based on previous studies. The model is based on the following hypothesis:

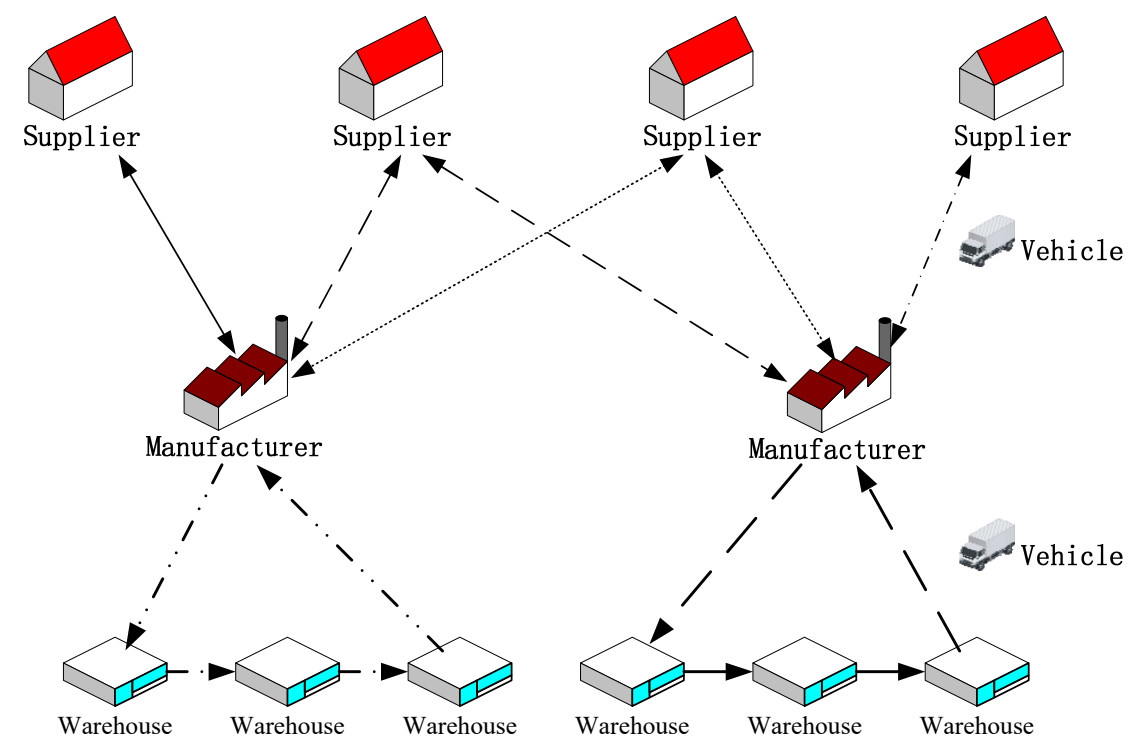

Figure 1. The distribution schematic diagram of VRPCSC.

(1) Each supplier owns all varieties of materials needed for the products, but the maximum supply quantity and cost of each material vary from one supplier to another; (2) One supplier can provide a variety of materials to multiple manufacturers at the same time, but the total quantity of each material supplied cannot exceed its maximum supply quantity; (3) A certain material of the products needed by warehouses can only be provided by one supplier; (4) The supplier can deliver materials to one manufacturer at a time, the vehicle must return to the original supplier immediately after the delivery. In other word, there is a one round-trip path between a supplier and a manufacturer, but the material delivery cost varies from one supplier to another; (5) All materials of the products needed by one warehouse must be manufactured into products by just one manufacturer, 
but different materials can be supplied from different suppliers and there is no competition between suppliers; (6) The products needed by warehouses can be processed by only one manufacturer, and delivered only by the vehicle of that manufacturer; (7) Different manufacturers have different processing costs, and they also have a different number of vehicles, vehicle models, and product delivery costs; (8) There is a linear relation between the total weight of the various materials before processing and the weight of products after processing; (9) The manufacturer's vehicle starts from the manufacturer's place, delivers the products to warehouses and returns to the original manufacturer's place after delivery; (10) The manufacturer's vehicle can deliver products only once. If it is used for delivery, the total weight of the products it delivers cannot exceed the maximum loading capacity of the vehicle.

\subsection{Mathematical Model}

In order to establish the mathematical model of VRPCSC more accurately, the mathematical notations are defined as follows:

\section{(1) Sets}

SS: Set of suppliers.

$S M$ : Set of manufacturers.

$S P$ : Set of warehouses.

$S L$ : Set of material types.

SK: Set of manufacturer vehicles.

\section{(2) Parameters}

$s$ : Element in set $S S, s \in S S$.

$m$ : Element in set $S M, m \in S M$.

$p$ : Element in set $S P, p \in S P$.

$l$ : Element in set $S L, l \in S L$.

$k$ : Element in set $S K, k \in S K$.

$S$ : Number of elements in the $S S$.

$M$ : Number of elements in the $S M$.

$P$ : Number of elements in the $S P$.

$L$ : Number of elements in the $S L$.

$K$ : Number of elements in the $S K$.

$e_{s l}$ : Maximum supply quantity of material $l$ of supplier $s$.

$c_{s l}$ : Cost per unit weight of material $l$ of supplier $s$.

$b_{s}$ : Delivery cost per unit distance of materials delivered by vehicles of supplier $s$.

$n_{m}$ : Number of vehicles owned by manufacturer $m$.

$c_{m}^{\prime}$ : Processing cost per unit weight of products made from materials by manufacturer $m$.

$b_{m k}^{\prime}$ : Delivery cost per unit distance of products delivered by vehicle $k$ of manufacturer $m$.

$u_{m k}$ : Maximum loading capacity of vehicle $k$ of manufacturer $m$.

$d_{s m}$ : Distance from supplier $s$ to manufacturer $m$.

$d_{m p}^{\prime}$ : Distance from manufacturer $m$ to warehouse $p$.

$d_{p p^{\prime}}^{\prime \prime}$ : Distance from warehouse $p$ to warehouse $p^{\prime}$.

$o_{p}$ : Weight of products needed by warehouse $p$.

$o_{p l}^{\prime}$ : Weight of material $l$ corresponding to the products needed by warehouse $p$.

\section{(3) Variables}

$y_{m k p}$ : If warehouse $p$ is the first warehouse distributed by vehicle $k$ of manufacturer $m, y_{m k p}=1$; otherwise, $y_{m k p}=0$.

$y_{m k p p^{\prime}}^{\prime}$ : If vehicle $k$ of manufacturer $m$ directly delivers products to warehouse $p^{\prime}$ after delivery to warehouse $p, y_{m k p p^{\prime}}^{\prime}=1$; otherwise, $y_{m k p p^{\prime}}^{\prime}=0$.

$y_{m k p}^{\prime \prime}$ : If warehouse $p$ is the last warehouse distributed by vehicle $k$ of manufacturer $m$, $y_{m k p}^{\prime \prime}=1$; otherwise, $y_{m k p}^{\prime \prime}=0$.

$g_{\text {smkpl }}$ : If the products delivered by vehicle $k$ of manufacturer $m$ to warehouse $p$ are made from material $l$ of supplier $s, g_{s m k p l}=1$; otherwise, $g_{s m k p l}=0$. 
$g_{s m}^{\prime}$ : If supplier $s$ uses the supplier's vehicle to deliver materials to manufacturer $m$, $g_{s m}^{\prime}=1$; otherwise, $g_{s m}^{\prime}=0$.

$g_{m k p}^{\prime \prime}$ : If vehicle $k$ of manufacturer $m$ is used to deliver products to warehouse $p$, $g_{m k p}^{\prime \prime}=1$; otherwise, $g_{m k p}^{\prime \prime}=0$.

\subsubsection{Objective Function}

According to the above description of VRPCSC, the whole logistics cost mainly consists of four parts. The first part is the purchase cost of materials (denoted as $Z_{\mathrm{PUR}}$ ). The second part is the delivery cost of materials from suppliers to manufacturers (denoted as $Z_{\text {STM }}$ ). The third part is the processing cost for the manufacturers to process materials into products (denoted as $Z_{\mathrm{PRO}}$ ). The fourth part is the delivery cost for the manufacturers to deliver the products to the warehouses (denoted as $Z_{\mathrm{MTS}}$ ). Then, the calculation methods for each part and the optimization objective of this paper are described in detail.

The purchase cost of materials can be calculated by the weights and prices of the materials, and the calculation method is shown in Formula (1):

$$
Z_{\mathrm{PUR}}=\sum_{s \in S S} \sum_{m \in S M} \sum_{k \in S K} \sum_{p \in S P} \sum_{l \in S L} g_{s m k p l} o^{\prime}{ }_{p l} c_{s l}
$$

On the other hand, since there is a one round-trip path between a supplier and a manufacturer, then $Z_{\mathrm{STM}}$ can be calculated as follows:

$$
Z_{\mathrm{STM}}=2 \times \sum_{s \in S S} \sum_{m \in S M} g_{s m}^{\prime} d_{s m} b_{s}
$$

It can be seen from Formula (2), that the unit delivery cost of the suppliers' vehicles and the delivery distances are related to $Z_{\mathrm{STM}}$. Further, several varieties of materials will be processed into products by manufacturers. The processing cost is related to the materials' weights and processing prices, which is shown in Formula (3).

$$
Z_{\mathrm{PRO}}=\sum_{m \in S M} \sum_{k \in S K} \sum_{p \in S P} g^{\prime \prime}{ }_{m k p} o_{p} c^{\prime}{ }_{m}
$$

At last, the products can be delivered by the manufacturers' vehicles. Since multiple warehouses' products can be delivered by a vehicle of a manufacturer at the same time, then $Z_{\text {MTS }}$ can be calculated by Formula (4).

$$
Z_{\mathrm{MTS}}=\sum_{m \in S M} \sum_{k \in S K} \sum_{p \in S P}\left(y_{m k p}+y^{\prime \prime}{ }_{m k p}\right) d^{\prime}{ }_{m p} b^{\prime}{ }_{m k}+\sum_{m \in S M} \sum_{k \in S K} \sum_{p \in S P} \sum_{p^{\prime} \in S P} y^{\prime}{ }_{m k p p^{\prime}} d^{\prime}{ }_{p p^{\prime}} b^{\prime}{ }_{m k}
$$

From Formula (1) to Formula (4), it can be obtained that the objective function is:

$$
Z_{\text {Total }}=\min \left(Z_{\mathrm{PUR}}+Z_{\mathrm{STM}}+Z_{\mathrm{PRO}}+Z_{\mathrm{MTS}}\right)
$$

The goal of this paper is to minimize the total cost of these four parts.

\subsubsection{Constraints}

After ensuring the objective of the VRPCSC, some constraints need to be confirmed in this model to make the VRPCSC fully satisfied with the problem description in Section 2.1. First, the relationship between products and materials satisfies linear constraints:

$$
o_{p}=\frac{o_{p 1}^{\prime}}{\sigma_{1}}=\frac{o_{p 2}^{\prime}}{\sigma_{2}}=\cdots=\frac{o_{p L}^{\prime}}{\sigma_{L}}
$$

where $\sigma_{1}, \sigma_{2}, \cdots, \sigma_{L}$ are all known real number constants. According to the product demands of the warehouses, the demands for purchased materials can be calculated by Formula (6). However, in the process of purchasing materials, each material provided 
by the supplier cannot exceed its maximum supply quantity. The constraint is shown in Formula (7):

$$
\sum_{m \in S M} \sum_{p \in S P} g_{s m k p l} o^{\prime} p l \leq e_{s l}, \forall s \in S S, \forall k \in S K, \forall l \in S L
$$

Further, in other to ensure that the supplier delivers the materials to the corresponding manufacturer at most by one vehicle, suppliers' vehicles should meet the following constraints:

$$
g_{s m}^{\prime}=\min \left\{1, \sum_{k \in S K} \sum_{p \in S P} \sum_{l \in S L} g_{s m k p l}\right\}, \forall s \in S S, \forall m \in S M
$$

When finished, the products will be delivered by the manufacturers' vehicles. In the same way, the weight of the products delivered by the manufacturers' vehicles cannot exceed their respective maximum loading capacities. The constraint is shown in Formula (9):

$$
\sum_{p \in S P} g^{\prime \prime}{ }_{m k p} o_{p} \leq u_{m k}, \forall m \in S M, \forall l \in S L
$$

In the process of delivering products to the warehouses, the manufacturers' vehicles should also meet the following constraints:

$$
\begin{gathered}
\sum_{m \in S M} \sum_{k \in S K} g^{\prime \prime}{ }_{m k p}=1, \forall p \in S P \\
\sum_{p \in S P} y_{m k p} \leq 1, \forall m \in S M, \forall k \in S K \\
\sum_{p \in S P} \sum_{p^{\prime} \in S P} y^{\prime}{ }_{m k p p^{\prime}} \leq \delta \sum_{p \in S P} y_{m k p}, \forall m \in S M, \forall k \in S K, \exists \delta \in R^{+} \\
\sum_{p \in S P T} \sum_{p^{\prime} \in S P T} m k p p^{\prime} \leq S P T-\gamma(S P T), \forall S P T \in S P, S P T \neq \varnothing, \forall m \in S M, \forall k \in S K
\end{gathered}
$$

where Formula (10) ensures that only one manufacturer delivers products to each warehouse; Formula (11) ensures that each manufacturer's vehicle can deliver products only once; Formula (12) ensures that the manufacturer's vehicle must start from the manufacturer's place to deliver products to the warehouse; Formula (13) ensures the continuous delivery process of one manufacturer's vehicle and $\gamma(S P T)$ denotes the minimum number of manufacturer's vehicles needed to serve all the warehouse in set SPT.

In addition, since the materials are related to the products, there are some constraints between the transportation of materials and corresponding products:

$$
\begin{gathered}
\sum_{s \in S S} \sum_{m \in S} \sum_{k \in S K} \sum_{p \in S P} g_{s m k p l}=1, \forall l \in S L \\
\sum_{s \in S S} \sum_{l \in S L} g_{s m k p l}=L \times g_{m k p}^{\prime \prime}, \forall m \in S M, \forall k \in S K, \forall p \in S P
\end{gathered}
$$

where Formula (14) ensures that each material corresponding to the products needed by each warehouse is provided by only one supplier, processed by one manufacturer and delivered by one manufacturer's vehicle; Formula (15) indicates the relationship between material delivery and product delivery.

Above all, the VRPCSC model can be established from Formula (1) to Formula (15). Then the algorithm of this model will be solved in detail. 


\section{The Proposed HCDBAVNS Algorithm}

BA is an intelligent evolutionary algorithm proposed by Yang X-S [23] that was inspired by the micro-bat echolocation principle. The BA simulates the process in nature where the bat searches for prey by echolocation, adjusts the wavelength of their emitted pulses and pulse emission rate depending on the proximity of the prey, and finally captures the prey, which is called a swarm optimization algorithm [24]. The BA mainly consists of four parts, i.e., bat position, bat velocity, bat frequency, and their corresponding update operations. Based on the characteristics of VRPCSC and our previous studies [20,21], this paper has proposed a HCDBAVNS algorithm to solve the model. The optimization framework of HCDBAVNS is shown in Figure 2.

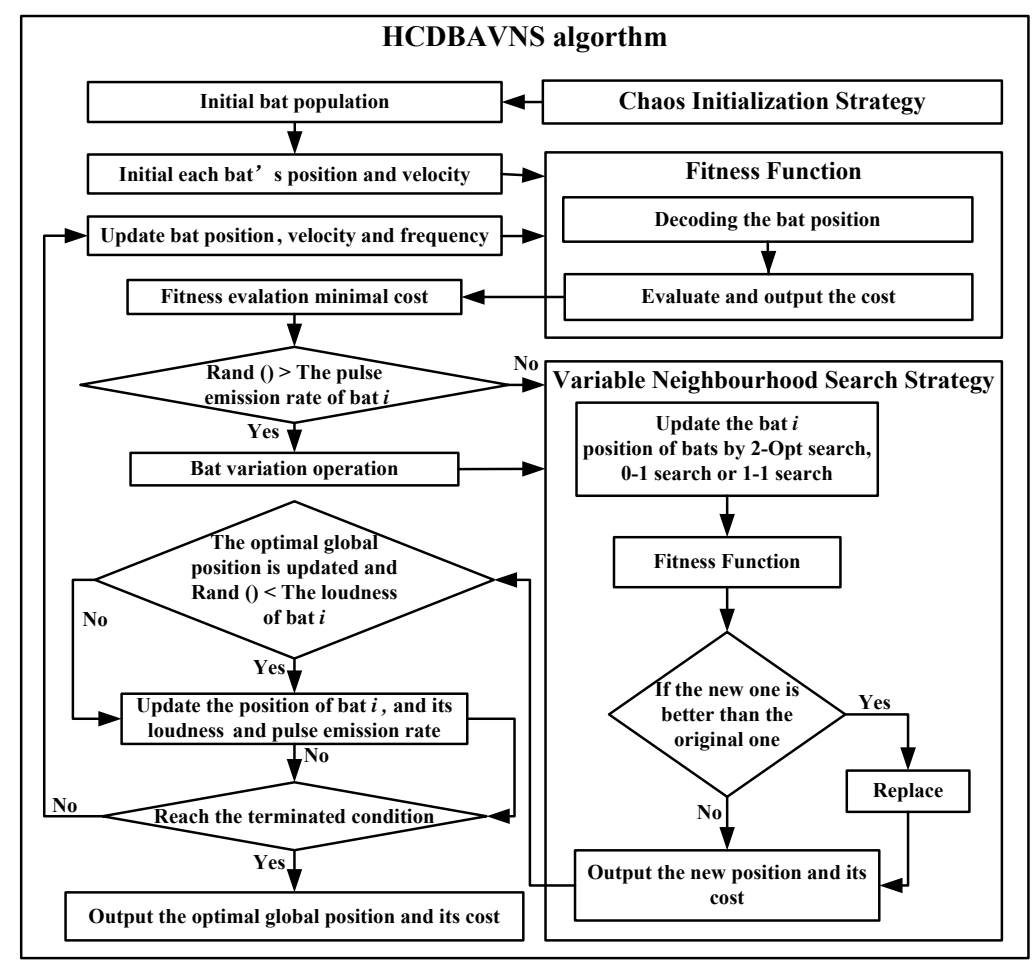

Figure 2. Optimization Framework of HCDBAVNS.

It can be seen from Figure 2, that there is a series of bat operations in HCDBAVNS, such as the updated operations of bat position, velocity, frequency, variation, loudness, and pulse emission rate. Then, HCDBAVNS also includes DCIS and VNS. In addition, the local search strategies, that is, 0-1 search, 1-1 search, and 2-Opt search are the critical parts of VNS. In the following sections, each component of the HCDBAVNS will be described in detail.

\subsection{Definition of Parameters and Operations}

\subsubsection{Bat Position, Velocity and Frequency}

The position of the bat is a key bridge between the solution model and the solution space. VRPCSC is a three-echelon supply chain structure, which consists of two stages of logistics and transportation scheduling. Then, the position of bat $i$ is defined as follows:

$$
\begin{gathered}
x_{i}=\left[x_{i}^{1}, x_{i}^{2}\right] \\
x_{i}^{1}=\left[x_{i 1}^{1}, x_{i 2}^{1}, \cdots, x_{i W}^{1}\right] \\
x_{i}^{2}=\left[x_{i 1}^{2}, x_{i 2}^{2}, \cdots, x_{i W^{\prime}}^{2}\right]
\end{gathered}
$$


where the dimensions of the first and second bat position are respectively $\mathrm{W}, W^{\prime}$. The detailed encoding and decoding methods for bat positions are described in Section 3.2.

On the other hand, BA is related to the bat velocity and frequency in the process of updating bat position. Similarly, this paper defines the velocity and frequency of bats as a two-layer structure to prepare for the following update operations of bats. Then, the velocity of bat $i$ is:

$$
\begin{gathered}
v_{i}=\left[v_{i}^{1}, v_{i}^{2}\right] \\
v_{i}^{1}=\left[v_{i 1}^{1}, v_{i 2}^{1}, \cdots, v_{i W}^{1}\right] \\
v_{i}^{2}=\left[v_{i 1}^{2}, v_{i 2}^{2}, \cdots, v_{i W^{\prime}}^{2}\right]
\end{gathered}
$$

where, $v_{i j}^{1}(j=1,2, \cdots, W)$ is an integer and $1 \leq v_{i j}^{1} \leq W ; v_{i j}^{2}\left(j=1,2, \cdots, W^{\prime}\right)$ is an integer and $1 \leq v_{i j}^{1} \leq W^{\prime}$. Further, the frequency of bat $i$ is:

$$
f_{i}=\left[f_{i}^{1}, f_{i}^{2}\right]
$$

where, $f_{i}^{1} \in[0,1] ; f_{i}^{2} \in[0,1]$.

\subsubsection{Update Operations of Bat Position, Velocity and Frequency}

The update operations of bat position, velocity and frequency mainly include four steps:

Supposing that, the position of bat $i$ is $x_{i}=\left[x_{i}^{1}, x_{i}^{2}\right], v_{i}=\left[v_{i}^{1}, v_{i}^{2}\right], f_{i}=\left[f_{i}^{1}, f_{i}^{2}\right]$, the optimal global position $x_{*}=\left[x_{*}^{1}, x_{*}^{2}\right]$, and the updated bat position, velocity, and frequency are $x_{i}^{\prime}, v_{i}^{\prime \prime \prime}$ and $f_{i}^{\prime}$, respectively.

(1) $x_{i}-x_{*}=v_{i}^{\prime}=\left[v_{i}^{\prime 1}, v_{i}^{\prime 2}\right]$ : For any $x_{i j}^{1} \in x_{i}^{1}, x_{* j}^{1} \in x_{*}^{1}, v_{i j}^{\prime 1} \in v_{i}^{\prime 1}$ and $j=1,2, \cdots, W$, if $x_{i j}^{1}=x_{* j}^{1}$, then $v_{i j}^{\prime 1}=0$; if $x_{i j}^{1} \neq x_{* j^{\prime}}^{1}$, then $v_{i j}^{\prime 1}=x_{* j}^{1} . v_{i}^{\prime 2}$ is obtained from $x_{i}^{2}$ and $x_{*}^{2}$ in the same way.

(2) $v_{i}^{\prime} \times f_{i}=v_{i}^{\prime \prime}=\left[v_{i}^{\prime \prime 1}, v_{i}^{\prime \prime 2}\right]$ : Let $f_{i}^{\prime}=\left[f_{i}^{\prime 1}, f_{i}^{\prime 2}\right], f_{r}$ is randomly generated and $f_{r} \in[0,1]$, frequency factor $\theta^{1}>1$ and $\theta^{2}>1$. For any $v_{i j}^{\prime 1} \in v_{i}^{\prime 1}, v_{i j}^{\prime \prime 1} \in v_{i}^{\prime \prime 1}$ and $j=1,2, \cdots, W$, if $f_{r}<f_{i}^{1}$, then $v_{i j}^{\prime \prime 1}=0, f_{i}^{\prime 1}=f_{i}^{1}$; if $f_{r} \geq f_{i}^{1}$, then $v_{i j}^{\prime \prime 1}=v_{i j}^{\prime 1}, f_{i}^{\prime 1}=f_{i}^{1}+\left(f_{r}-f_{i}^{1}\right) / \theta^{1}$. $v_{i}^{\prime \prime 2}$ and $f_{i}^{2}$ are obtained from $f_{r}$ and $\theta^{2}$ in the same way.

(3) $v_{i}+v_{i}^{\prime \prime}=v_{i}^{\prime \prime \prime}=\left[v_{i}^{\prime \prime 1}, v_{i}^{\prime \prime 2}\right]:$ For any $v_{i j}^{1} \in v_{i}^{1}, v_{i j}^{\prime \prime \prime} \in v_{i}^{\prime \prime 1}, v_{i j}^{\prime \prime 1} \in v_{i}^{\prime \prime 1}, v_{i j}^{\prime \prime \prime}{ }^{1} \in v_{i}^{\prime \prime \prime}{ }^{1}$ and $j=1,2, \cdots, W$, if $\operatorname{rand}()<0.5$, then $v_{i j}^{\prime \prime \prime}=v_{i j}^{1}$; if $\operatorname{rand}() \geq 0.5$, then $v_{i j}^{\prime \prime \prime}=v_{i j}^{\prime \prime 1} \cdot v_{i}^{\prime \prime \prime}{ }^{2}$ is obtained from $v_{i}^{2}$ and $v_{i}^{\prime \prime 2}$ in the same way.

(4) $x_{i}+v_{i}^{\prime \prime \prime}=x_{i}^{\prime}=\left[x_{i}^{\prime 1}, x_{i}^{\prime 2}\right]$ : Let $x_{i}^{\prime 1}=x_{i}^{1}$, when $v_{i j}^{\prime \prime \prime} \neq 0$, the component of $x_{i}^{\prime 1}$ at position $x_{i j}{ }^{1}$ is exchanged with its component at position $v_{i j}^{\prime \prime \prime}{ }^{1}(j=1,2, \cdots, W) . x_{i}^{\prime 2}$ is obtained from $x_{i}{ }^{2}$ and $x_{i}^{\prime \prime \prime}$ in the same way. A instance is shown in Figure 3. 


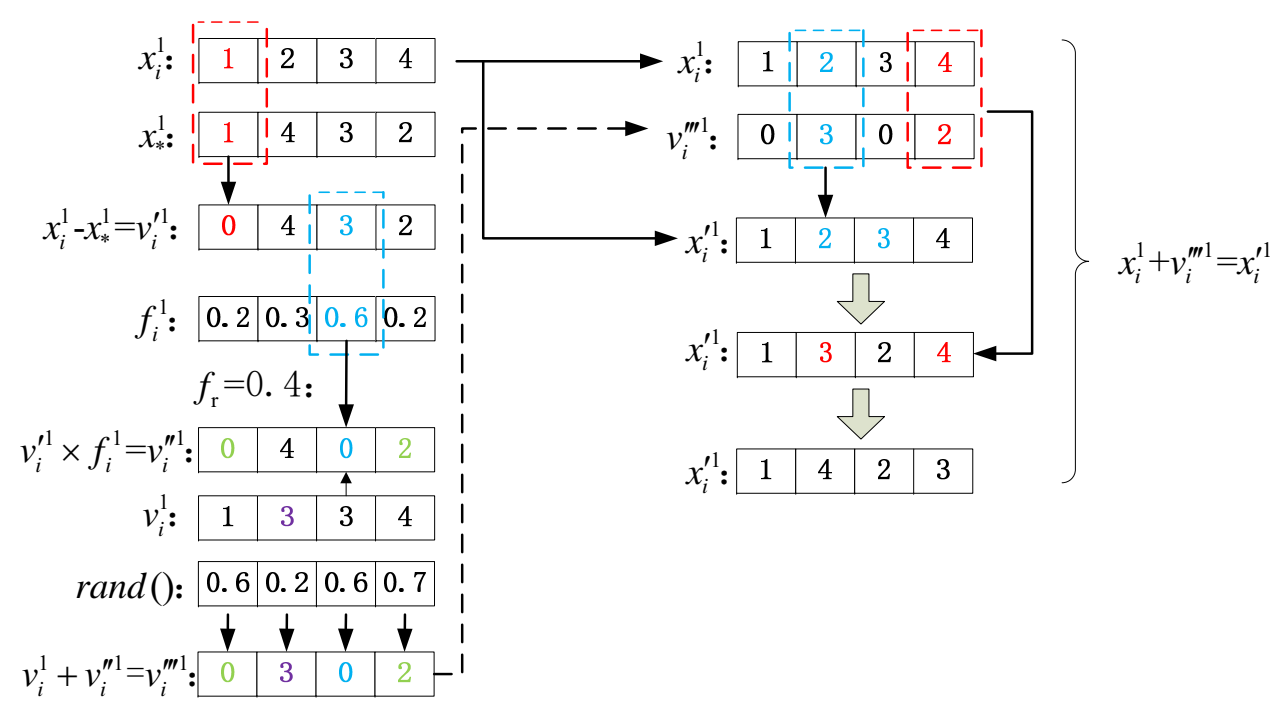

Figure 3. An instance for the update operations of bat position, velocity, and frequency.

In Figure 3, assuming that $x_{i}^{1}=\{1,2,3,4\}$ and $x_{*}^{1}=\{1,4,3,2\}$, then $x_{i}^{1}-x_{*}^{1}=$ $v_{i}^{\prime 1}=\{0,4,3,2\}$. Second, assuming that $f_{i}^{1}=\{0.2,0.3,0.6,0.2\}$ and $f_{r}=0.4$, then $v_{i}^{\prime 1} \times$ $f_{i}^{1}=v_{i}^{\prime \prime 1}=\{0,4,0,2\}$. Third, assuming that $v_{i}^{1}=\{1,3,3,4\}$ and the random values is $\{0.6,0.2,0.6,0.7\}$, then $v_{i}^{1}+v_{i}^{\prime \prime}{ }^{1}=v_{i}^{\prime \prime \prime}{ }^{1}=\{0,3,0,2\}$. Based on the $x_{i}^{1}$ and $v_{i}^{\prime \prime \prime}{ }^{1}, x_{i}+v_{i}^{\prime \prime \prime}=$ $x_{i}^{\prime}=\{1,4,2,3\}$.

\subsubsection{Bat Variation Operation}

Supposing that, the position of bat $i$ is $x_{i}=\left[x_{i}^{1}, x_{i}^{2}\right]$. Let $j$ and $w$ be randomly generated unequal integers $(1 \leq j \leq W, 1 \leq w \leq W)$, and exchange the $j$-th component and $w$-th component of $x_{i}^{1} \cdot x_{i}^{2}$ is obtained in the same way.

\subsubsection{Update Operations of the Bat Loudness and Pulse Emission Rate}

Supposing $R_{i}^{0} \in[0,1]$ and $A_{i}^{t} \in[0,1]$ are the initial pulse emission rate and loudness of bat $i$ at iteration $t$. Then, at iteration $t+1$, its loudness $A_{i}^{t+1}=\alpha A_{i}^{t}$, and pulse emission rate $R_{i}^{t+1}=R_{i}^{0} \times[1-\exp (-\gamma t)]$, where the loudness factor $0<\alpha<1$ and pulse emission rate factor $\gamma>0$.

\subsection{Encoding and Decoding Schemes}

The encoding and decoding schemes are important steps to solve the optimization problem, which affects the quality of the final solution. Finally, they are described in detail.

\subsubsection{Encoding Scheme}

(1) Encoding of materials needed for products: The products are made from a variety of materials, but the materials of the products needed by the same warehouse can be provided by different suppliers. Therefore, a unique mark must be given to the material corresponding to the products needed by each warehouse. Since the number of warehouses is $P$ and the number of material types needed for products $L$, the material $l$ corresponding to the products needed by warehouse $p$ is coded as $p \times l$. The material codes corresponding to all products will form a sequence $[1,2, \cdots, P \times L]$;

(2) Encoding of the first-part bat position: Let the dimension of $x_{i}^{1}$ be $W=P \times L+$ $S-1$, which is a permutation of the sequence of integers $[1,2, \cdots, W]$;

(3) Encoding of the second-part bat position: Let the dimension of $x_{i}^{2}$ be $W^{\prime}=P+$ $\sum_{m=1}^{M} n_{m}-1$, which is a permutation of the sequence of integers $\left[1,2, \cdots, W^{\prime}\right]$. 


\subsubsection{Decoding Scheme}

The first-part bat position $x_{i}^{1}$ is used to determine the supplier of a certain material of the products needed by the warehouse.

(1) $x_{i j}^{1}=1,2, \cdots, P \times L(1 \leq j \leq W)$ represents the serial number of a certain material for the warehouse, so as to ensure that a certain material of the products needed by each warehouse is provided by only one supplier;

(2) $x_{i j}^{1}>P(1 \leq j \leq W)$ splits $x_{i}^{1}$ into $S$ segments. From left to right, the segment $s$ represents the set of materials provided by supplier $s$ corresponding to the products needed by the warehouse, and $s=1,2, \cdots, S$.

The second-part bat position $x_{i}^{2}$ is used to determine the manufacturer, making the products needed by the warehouse and the manufacturer's vehicle delivering the products.

(1) $x_{i j}^{2} \leq P\left(1 \leq j \leq W^{\prime}\right)$ represents the serial number of the warehouse, so as to ensure that the products needed by each warehouse are made by only one manufacturer and delivered by the manufacturer's vehicle;

(2) $x_{i j}^{2}>P\left(1 \leq j \leq W^{\prime}\right)$ splits $x_{i}^{2}$ into $\sum_{m=1}^{M} n_{m}$ segments. From left to right, the segment $\left[\sum_{i=1}^{m-1} n_{i}, \sum_{i=1}^{m} n_{i}\right]$ represents the vehicle belonging to the manufacturer $m$, and $m=$ $1,2, \cdots, M$. The $n_{m}$ segments belonging to the manufacturer $m$ represent the delivery path of vehicle $k$ of the manufacturer $m$ from left to right, and $k=1,2, \cdots, n_{m}$.

Since $x_{i}^{1}$ determines the supplier of a certain material of the products needed by the warehouse, and $x_{i}^{2}$ determines the manufacturer delivering the products needed by the warehouse, it is easy to determine the manufacturer processing a certain material provided by each supplier.

First, the materials corresponding to the products needed by each warehouse are encoded, as shown in Figure 4. After confirming the serial number of each material corresponding to the products needed by the warehouse, the bat position can be encoded, as shown in Figure 5.

In the first-part bat position, position components 12 and 11 act as supplier delimiters, dividing the first-part position into three segments, i.e., supplier 1 is responsible for providing materials 1, 3, 5, 10; supplier 2 is responsible for providing materials 2, 4, 6, 7; and supplier 3 is responsible for providing materials 8,9 .

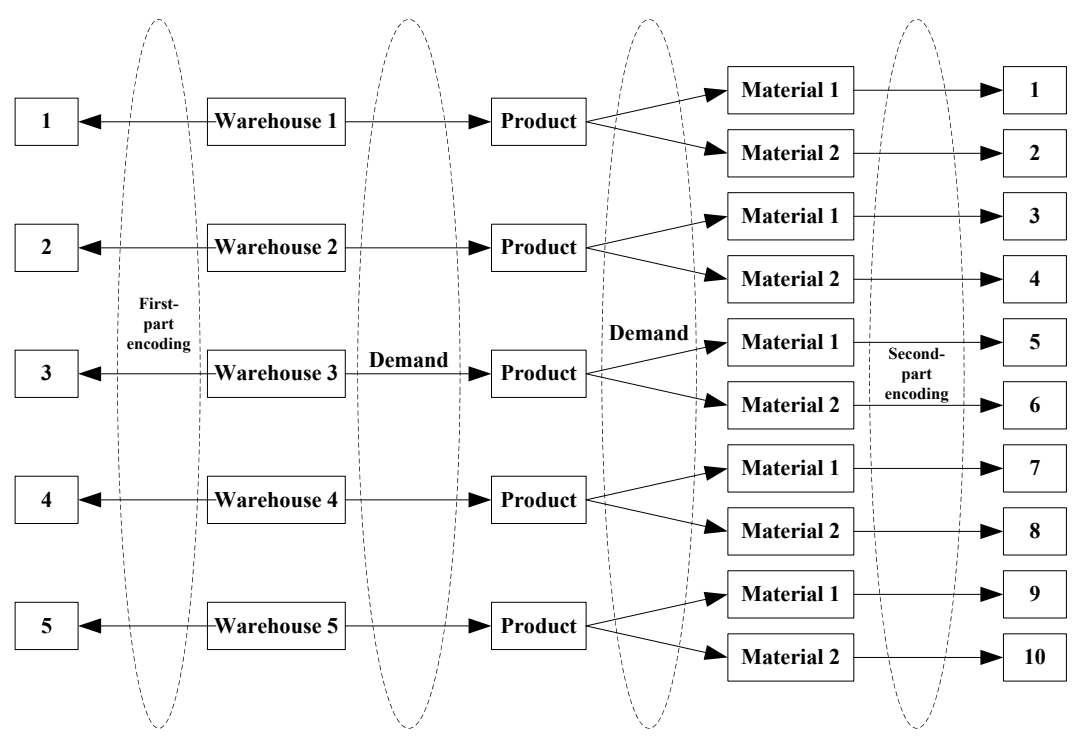

Figure 4. An instance for encoding the materials of products. 


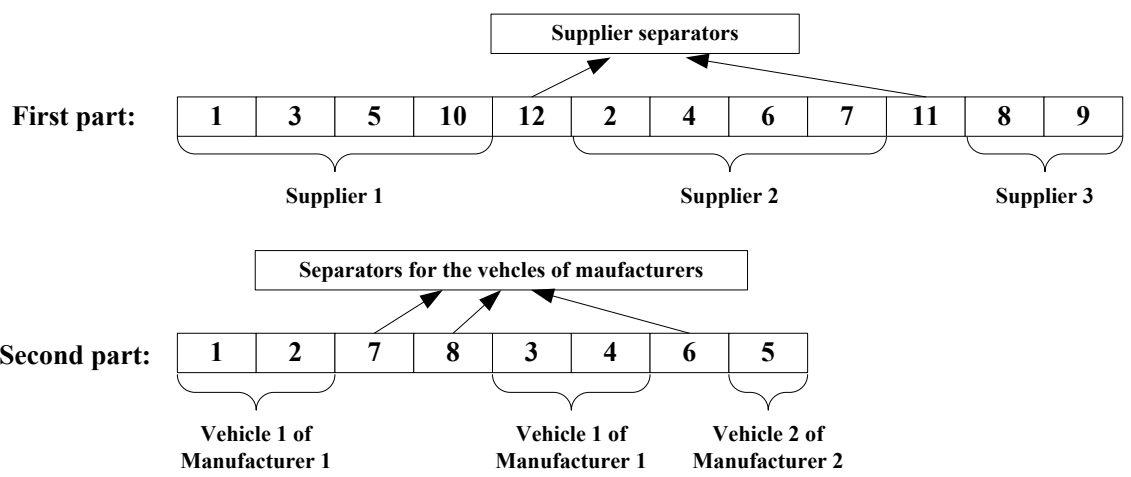

Figure 5. An instance for encoding the bat position.

In the second-part position, position components 6,7 , and 8 act as the manufacturer's vehicle delimiters, dividing the second-part bat position into four segments, i.e., vehicle 1 of manufacturer 1 is responsible for delivering the products of warehouses 1 and 2; vehicle 2 of manufacturer 1 is an empty vehicle (i.e., this vehicle is not used); vehicle 1 of manufacturer 2 is responsible for delivering the products of warehouses 3 and 4; and vehicle 2 of manufacturer 2 is responsible for delivering the products of warehouse 5 .

After determining the first-part and second-part bat positions, supplier 1 should deliver materials 1 and 3 to manufacturer 1 , and materials 5 and 10 to manufacturer 2; supplier 2 should deliver materials 2 and 4 to manufacturer 1 , and materials 6 and 7 to manufacturer 2; supplier 3 should deliver materials 8 and 9 to manufacturer 2 . The delivery path after decoding is shown in Figure 6.

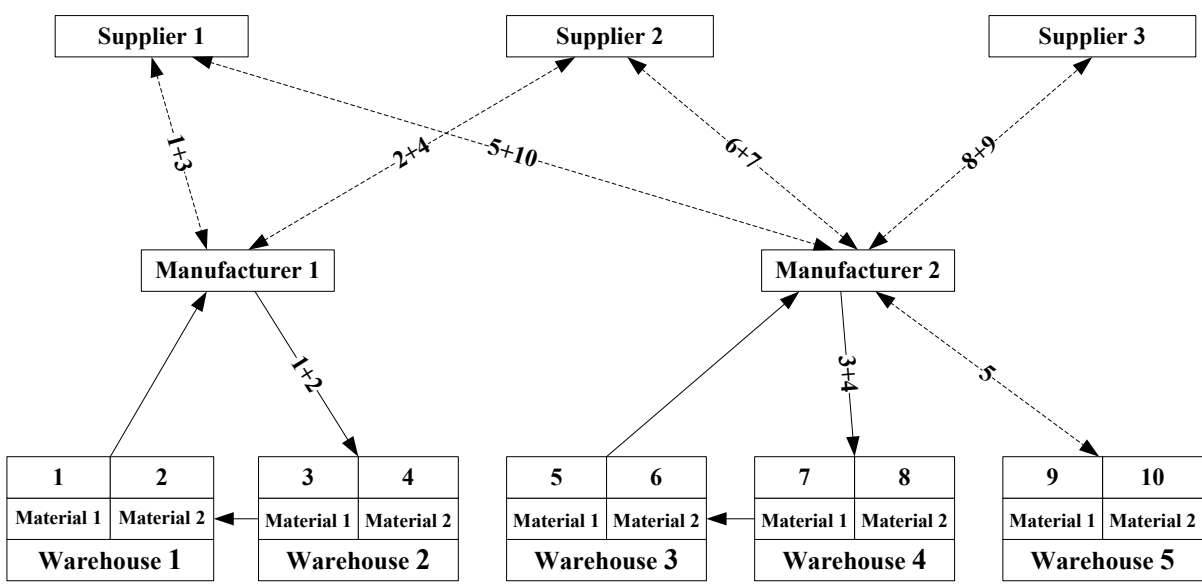

Figure 6. Instance for decoding the bat position.

\subsection{Discrete Chaos Initialization Strategy}

The chaos optimization algorithm is an optimization algorithm characterized by randomness, ergodicity, and regularity. Scholars often adopt it to generate a set of initialized random sequences with ergodicity and pseudo-randomness, so as to strengthen the prophase convergence rate and overall convergence effect of intelligent algorithms [25]. According to our previous works [26], DCIS is used to generate the pseudo-random sequence in this paper, which is based on Logistic mapping (shown in Formula (23)).

$$
z_{i+1}=\mu z_{i}\left(1-z_{i}\right)
$$

where, $0 \leq z_{i} \leq 1, z_{i} \neq 0.25,0.5,0.75, i=0,1,2, \cdots, \mu=4$.

Further, we adopt the all-permutation structure theory [27] to establish the corresponding relation between the serial number and the path. Finally, the initial population of bats can be preferentially generated by Formula (23) using the characteristics of chaos. 


\subsection{Fitness Function}

The delivery path among suppliers, manufacturers, and warehouses can be obtained through encoding and decoding the bat position. However, it cannot be proved that the derived delivery path is a feasible solution, because the path may violate the constraint conditions of Formulas (13) and (14). Therefore, this paper deals with the constraints of Formulas (13) and (14) using a punishment mechanism to punish the infeasible solution. Further, it is found that there is no quantitative relationship among Formulas (5), (13), and (14). If the sum of the three formulas is directly used for fitness comparison, it is not conducive to controlling the optimization direction of the algorithm. Second, it is found that the optimal path must first satisfy Formulas (13) and (14) and then converge to the optimal direction of Formula (5). Therefore, on the basis of the punishment mechanism, a vector mechanism has been added to the fitness function in this paper. After using the punishment and vector mechanisms, the fitness function of bat $i$ can be derived from Formula (5):

$$
\begin{gathered}
G_{i}=\left\{G_{i 1}, G_{i 2}, G_{i 3}\right\} \\
G_{i 1}=\sum_{s \in S S} \sum_{l \in S L} \max \left\{0, \sum_{m \in S M} \sum_{k \in S K} \sum_{p \in S P} g_{s m k p l} o^{\prime}{ }_{p l}-e_{s l}\right\} \\
G_{i 2}=\sum_{m \in S M} \sum_{k \in S K} \max \left\{0, \sum_{p \in S P} g^{\prime \prime}{ }_{m k p} o_{p}-u_{m k}\right\} \\
G_{i 3}=\sum_{S \in S S} \sum_{m \in S M} \sum_{k \in S K} \sum_{p \in S P} \sum_{l \in S L} g_{s m k p l} o^{\prime}{ }_{p l} c_{s l}+2 \times \sum_{S \in S S} \sum_{m \in S M} g^{\prime}{ }_{s m} d_{s m} b_{S}+ \\
\sum_{m \in S M} \sum_{k \in S K} \sum_{p \in S P} g_{g^{\prime \prime}}{ }_{m k p} o_{p} c^{\prime}{ }_{m}+\sum_{m \in S M} \sum_{k \in S K} \sum_{p \in S P}\left(y_{m k p}+y^{\prime \prime}{ }_{m k p}\right) d^{\prime}{ }_{m p} b^{\prime}{ }_{m k}+ \\
\sum_{m \in S M} \sum_{k \in S K} \sum_{p \in S P} \sum_{p^{\prime} \in S P} y^{\prime}{ }_{m k p p^{\prime}} d^{\prime}{ }_{p p^{\prime}} b^{\prime}{ }_{m k}
\end{gathered}
$$

where $G_{i 1}$ and $G_{i 2}$ are the punishments for violating the constraint of Formulas (13) and (14) respectively, and $G_{i 3}$ is the original target.

As can be seen from Formula (24), the fitness function $G_{i 1}$ is a three-dimensional value, and the commonly-used comparison method of one-dimensional numerical values is not suitable for fitness comparison in this paper. Hence, this paper has proposed a comparison method based on vector mechanism.

Supposing that the fitness of delivery path 1 is $G_{1}=\left\{G_{11}, G_{12}, G_{13}\right\}$, the fitness of delivery path 2 is $G_{2}=\left\{G_{21}, G_{22}, G_{23}\right\}$, and the optimal fitness is $G_{b e s t}$, the flow chart is shown in Figure 7. 


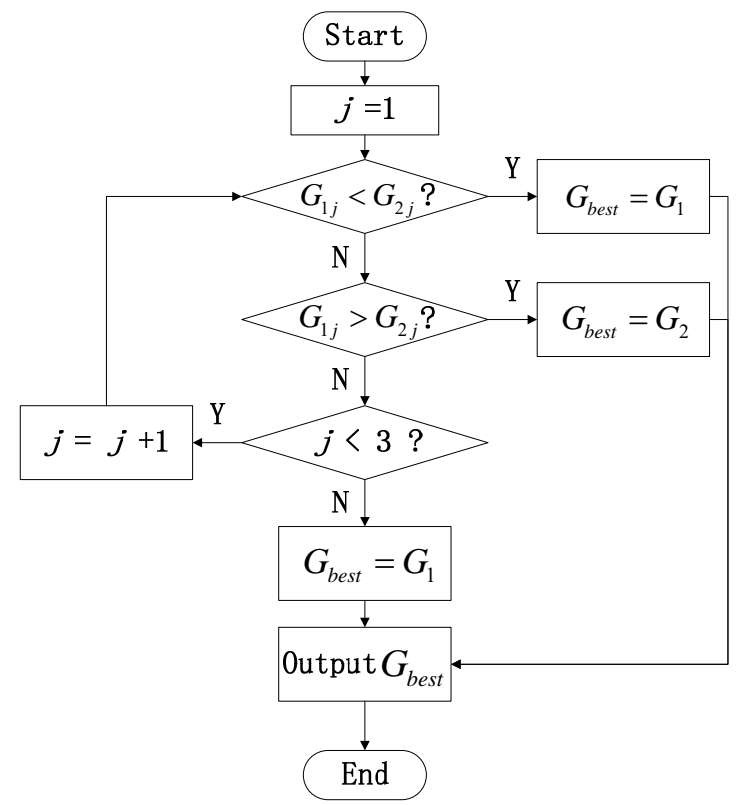

Figure 7. Flowchart of the fitness comparison based on vectorial mechanism.

\subsection{Variable Neighborhood Search Strategy}

The local search is a supplement to intelligent algorithms, and it can enhance the search capability of the algorithm [28]. Therefore, this paper introduces 2-Opt search, 0-1 search and 1-1 search, and proposes a VNS strategy [29]. In order to avoid excessive disturbance to the search direction, it is stipulated in this strategy that when one part of the bat position changes in the process of local optimization, the other part of bat position remains unchanged. The specific steps of VNS are as follows:

Step 1: 2-Opt search. 2-Opt search is carried out on the delivery path of a manufacturer's vehicle, until the vehicle's delivery path cannot be further improved.

Step 2: 0-1 search. For the first-part bat position, a material point of one supplier is inserted into that of another supplier to form a new bat position. If the new bat position is better, then the new bat position is accepted, and 0-1 search for this part of bat position is repeated until no longer updated after $L$ times. For the second-part bat position, a warehouse point of one manufacturer's vehicle is inserted into that of another manufacturer's vehicle, and 2-Opt search is performed on the two vehicles, respectively, to form a new bat position. If the new bat position is better, then the new bat position is accepted, and 0-1 search for this part of bat position is repeated until no longer updated after $L$ times.

Step 3: 1-1 search. It is similar to the 0-1 search. The difference lies in that $0-1$ search is the insertion of points, while 1-1 search is the exchange of two points.

The VNS in this paper just exchanges the order of the components of bat position according to certain rules. The obtained bat position still conforms to the encoding definition of the bat position in Section 3.1, and a complete VRPCSC path can be obtained by decoding. The pseudocode of HCDBAVNS is shown as Algorithm 1. 


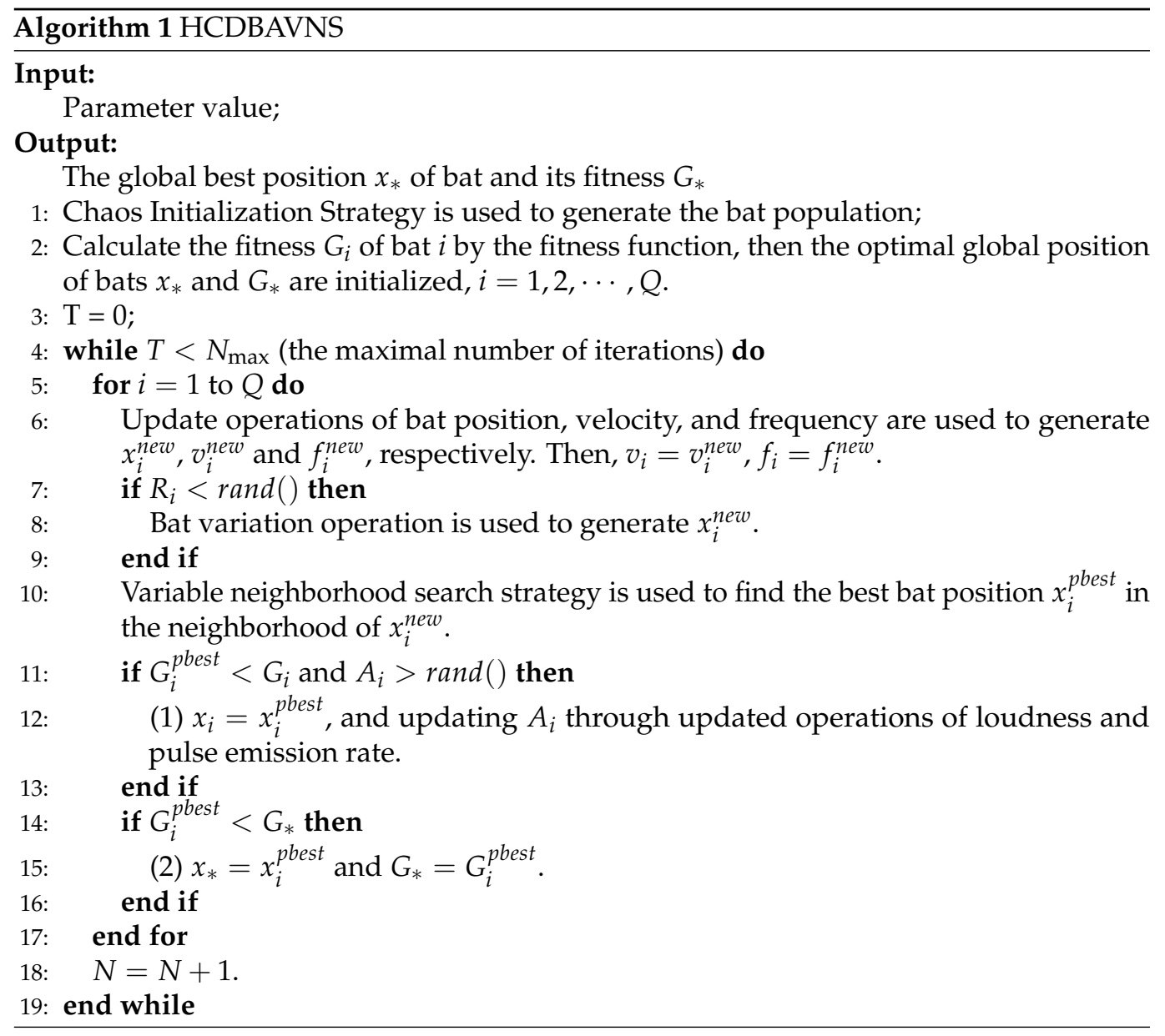

\section{Experiments}

\subsection{Experimental Instances}

Since the VRPCSC model has no benchmark instances, this paper randomly generates 20 test instances to evaluate the algorithm according to the size of instances in Table 1 and the parameter values of instances in Table 2. These instances are divided into four groups, each group has five instances, and each instance is marked as P01, P02, ..., P20, respectively.

Table 1. The scale of Instances.

\begin{tabular}{ccccccc}
\hline Group & $\boldsymbol{S}$ & $\boldsymbol{M}$ & $\boldsymbol{n}_{\boldsymbol{m}}$ & $\boldsymbol{P}$ & $\boldsymbol{L}$ & $\begin{array}{c}\text { Relationship between } \\
\text { Materials and Products }\end{array}$ \\
\hline $\mathrm{G} 1$ & 3 & 2 & 3 & 10 & 2 & $o_{p}=\frac{o^{\prime} p 1}{1}=\frac{o^{\prime} p 2}{1}[\mathrm{t}]$ \\
$\mathrm{G} 2$ & 4 & 3 & 3 & 20 & 2 & $o_{p}=\frac{o_{p 1}^{\prime}}{1}=\frac{o_{p 2}^{\prime}}{1}$ \\
$\mathrm{G} 3$ & 3 & 2 & 3 & 10 & 3 & $o_{p}=\frac{o_{p 1}^{\prime}=\frac{o_{p 2}^{\prime}}{2}=\frac{o_{p 3}^{\prime}}{2}}{2}=o_{p}=\frac{o_{p 1}^{\prime}}{2}=\frac{o_{p 2}^{\prime}}{2}=\frac{o^{\prime} p 3}{1}[\mathrm{~b}]$ \\
\hline
\end{tabular}


Table 2. The ranges of some parameters of instances.

\begin{tabular}{cc}
\hline Parameter & Range \\
\hline $\mathrm{X}$ and $\mathrm{Y}$ coordinates & Rand $(0,500)[\mathrm{t}]$ \\
$e_{s}$ & Rand $(20,70)$ \\
$c_{s}$ & Rand $(1000,1500)$ \\
$b_{s}$ & Rand $(10,15)$ \\
$u_{m k}$ & Rand $(0,3)^{*} 10$ \\
$c_{m}^{\prime}$ & Rand $(1500,1800)$ \\
$b_{m k}^{\prime}$ & Rand $(3,5)$ \\
$o_{p}$ & Rand $(1,10)[\mathrm{b}]$ \\
\hline
\end{tabular}

\subsection{Experimental Environment}

The simulation environment of the experiment uses a Windows 7 operating system, i7 processor, and 4G memory. The programming language is $\mathrm{C}++$. All the algorithms are implemented and executed in this experimental environment. Each instance is independently solved by the corresponding algorithm 10 times to obtain experimental results.

\subsection{Key Experimental Parameters}

The values of key experimental parameters have a great influence on the solving capability of intelligent algorithms. Thus, in order to enable the algorithm to solve the VRPCSC more effectively, four VRPCSC instances are solved using HCDBAVNS with different values of $\theta^{1}, \theta^{2}, \gamma$ and $\alpha$ (other parameters: $Q=30, L=100, M I T \leq 3000$ ). The results are shown in Tables $3-5$, where the unit of time is second.

Table 3. The result of instances by HCDBAVNS with different $\theta^{1}$ and $\theta^{2}$.

\begin{tabular}{|c|c|c|c|c|c|c|c|c|c|}
\hline \multirow{2}{*}{ Instance } & \multicolumn{3}{|c|}{$\begin{array}{c}\theta^{1}=0.5 \times W, \theta^{2}=0.5 \times W^{\prime} \\
\alpha=0.999, \gamma=0.001\end{array}$} & \multicolumn{3}{|c|}{$\begin{aligned} \theta^{1} & =W, \theta^{2}=2 \times W^{\prime} \\
\alpha & =0.999, \gamma=0.001\end{aligned}$} & \multicolumn{3}{|c|}{$\begin{array}{c}\theta^{1}=2 \times W, \theta^{2}=W^{\prime} \\
\alpha=0.999, \gamma=0.001\end{array}$} \\
\hline & $\begin{array}{c}\text { Best } \\
\text { Solution }\end{array}$ & $\begin{array}{l}\text { Average } \\
\text { Solution }\end{array}$ & Time & $\begin{array}{l}\text { Best } \\
\text { Solution }\end{array}$ & $\begin{array}{l}\text { Average } \\
\text { Solution }\end{array}$ & Time & $\begin{array}{c}\text { Best } \\
\text { Solution }\end{array}$ & $\begin{array}{l}\text { Average } \\
\text { Solution }\end{array}$ & Time \\
\hline P01 & 245,399 & $245,399.0$ & 4.7 & 245,399 & $245,399.0$ & 4.3 & 245,399 & $245,399.0$ & 4.8 \\
\hline P06 & 454,497 & $454,891.2$ & 43.5 & 450,664 & $453,527.2$ & 45.9 & 452,069 & $453,797.8$ & 44.6 \\
\hline P11 & 379,602 & $379,602.0$ & 17.4 & 379,602 & $379,602.0$ & 14.1 & 379,602 & $379,602.0$ & 18.6 \\
\hline P16 & 939,685 & $941,535.4$ & 56.7 & 938,095 & $940,699.0$ & 59.2 & 938,336 & $941,260.2$ & 59.6 \\
\hline
\end{tabular}

1. In Table 3, $\alpha$ and $\gamma$ have the same value. When $\theta^{1}=W$ and $\theta^{2}=W^{\prime}$, the HCDBAVNS has the most balanced performance in optimization capability and time consumption.

Table 4. The result of instances by HCDBAVNS with different $\alpha$.

\begin{tabular}{|c|c|c|c|c|c|c|c|c|c|}
\hline \multirow{2}{*}{ Instance } & \multicolumn{3}{|c|}{$\begin{array}{l}\theta^{1}=W, \theta^{2}=W^{\prime} \\
\alpha=0.9, \gamma=0.001\end{array}$} & \multicolumn{3}{|c|}{$\begin{array}{c}\theta^{1}=W, \theta^{2}=W^{\prime} \\
\alpha=0.99, \gamma=0.001\end{array}$} & \multicolumn{3}{|c|}{$\begin{array}{c}\theta^{1}=W, \theta^{2}=W^{\prime} \\
\alpha=0.999, \gamma=0.001\end{array}$} \\
\hline & $\begin{array}{c}\text { Best } \\
\text { Solution }\end{array}$ & $\begin{array}{l}\text { Average } \\
\text { Solution }\end{array}$ & Time & $\begin{array}{c}\text { Best } \\
\text { Solution }\end{array}$ & $\begin{array}{l}\text { Average } \\
\text { Solution }\end{array}$ & Time & $\begin{array}{c}\text { Best } \\
\text { Solution }\end{array}$ & $\begin{array}{l}\text { Average } \\
\text { Solution }\end{array}$ & Time \\
\hline P01 & 245,399 & $245,399.0$ & 5.1 & 245,399 & $245,399.0$ & 4.7 & 245,399 & $245,399.0$ & $4.3[\mathrm{t}]$ \\
\hline P06 & 452,935 & $454,656.6$ & 47.7 & 451,918 & $453,691.6$ & 46.1 & 450,664 & $453,527.2$ & 45.9 \\
\hline P11 & 379,602 & $379,602.0$ & 18.3 & 379,602 & $379,602.0$ & 16.3 & 379,602 & $379,602.0$ & 14.1 \\
\hline P16 & 941,560 & $943,788.6$ & 62.3 & 939,532 & $940,811.0$ & 60.5 & 938,095 & $940,699.0$ & $59.2[\mathrm{~b}]$ \\
\hline
\end{tabular}

2. In Table $4, \theta^{1}, \theta^{2}$ and $\gamma$ have the same value. As the value of $\alpha$ increases, HCDBAVNS has increasingly better optimization capability but slightly decreased time consumption. 
Table 5. The result of instances by HCDBAVNS with different $\gamma$.

\begin{tabular}{|c|c|c|c|c|c|c|c|c|c|}
\hline \multirow{2}{*}{ Instance } & \multicolumn{3}{|c|}{$\begin{array}{c}\theta^{1}=W, \theta^{2}=W^{\prime} \\
\alpha=0.999, \gamma=0.001\end{array}$} & \multicolumn{3}{|c|}{$\begin{array}{c}\theta^{1}=W, \theta^{2}=W^{\prime} \\
\alpha=0.999, \gamma=0.01\end{array}$} & \multicolumn{3}{|c|}{$\begin{array}{l}\theta^{1}=W, \theta^{2}=W^{\prime} \\
\alpha=0.999, \gamma=0.5\end{array}$} \\
\hline & $\begin{array}{c}\text { Best } \\
\text { Solution }\end{array}$ & $\begin{array}{l}\text { Average } \\
\text { Solution }\end{array}$ & Time & $\begin{array}{c}\text { Best } \\
\text { Solution }\end{array}$ & $\begin{array}{l}\text { Average } \\
\text { Solution }\end{array}$ & Time & $\begin{array}{c}\text { Best } \\
\text { Solution }\end{array}$ & $\begin{array}{l}\text { Average } \\
\text { Solution }\end{array}$ & Time \\
\hline P01 & 245,399 & $245,399.0$ & 4.3 & 245,399 & $245,399.0$ & 4.7 & 245,399 & $245,399.0$ & $4.6[\mathrm{t}]$ \\
\hline P06 & 450,664 & $453,527.2$ & 45.9 & 452,229 & $453,827.0$ & 43.7 & 453,026 & $454,184.4$ & 41.6 \\
\hline P11 & 379,602 & $379,602.0$ & 14.1 & 379,602 & $379,602.0$ & 17.1 & 379,602 & $379,602.0$ & 17.3 \\
\hline P16 & 938,095 & $940,699.0$ & 59.2 & 939,359 & $941,121.6$ & 53.2 & 942,008 & $942,730.2$ & $55.7[\mathrm{~b}]$ \\
\hline
\end{tabular}

3. In Table $5, \theta^{1}, \theta^{2}$ and $\alpha$ have the same value. As the value of $\gamma$ decreases, HCDBAVNS has the generally the same time consumption but increasingly stronger optimization capability.

It can be seen that among the seven combinations of values that HCDBAVNS has the best performance when $\theta^{1}=W, \theta^{2}=W^{\prime}, \alpha=0.999$ and $\gamma=0.001$. Therefore, $Q=30$, $L=100, M I T \leq 3000, \theta^{1}=W, \theta^{2}=W^{\prime}, \alpha=0.999$ and $\gamma=0.001$ will be set in the following experiments.

\subsection{Experimental Results and Analysis}

In this part, 2 experiments are performed to prove the effectiveness and the optimization ability of the algorithm, respectively.

\subsubsection{Experiment 1}

In order to analyse the solving effect of HCDBAVNS in detail, this paper selects the experimental results of the instance P01 for specific analysis. The information of instance P01 is shown in Tables 6-8.

Table 6. Supplier information of P01.

\begin{tabular}{cccccccc}
\hline Supplier & X Coordinate & Y Coordinate & $\boldsymbol{b}_{\boldsymbol{s}}$ & $\boldsymbol{c}_{\boldsymbol{s} \mathbf{1}}$ & $\boldsymbol{e}_{\boldsymbol{s} \mathbf{1}}$ & $\boldsymbol{c}_{\boldsymbol{s} \mathbf{2}}$ & $\boldsymbol{e}_{\boldsymbol{s} \mathbf{2}}$ \\
\hline SUP1 & 99 & 236 & 10 & 1027 & 38 & 1200 & $26[\mathrm{t}]$ \\
SUP2 & 342 & 29 & 14 & 1072 & 21 & 1079 & 30 \\
SUP3 & 78 & 242 & 14 & 1067 & 24 & 1051 & $36[\mathrm{~b}]$ \\
\hline
\end{tabular}

Table 7. Manufacturer information of P01.

\begin{tabular}{|c|c|c|c|c|c|c|c|}
\hline \multirow{2}{*}{$\begin{array}{c}\text { Manufacturer } \\
\text { Tab }\end{array}$} & \multirow{2}{*}{ X Coordinate } & \multirow{2}{*}{ Y Coordinate } & \multirow{2}{*}{$b_{m k}^{\prime}$} & \multirow{2}{*}{$c_{m}^{\prime}$} & \multirow{2}{*}{$n_{m}$} & \multicolumn{2}{|c|}{ Vehicle Information } \\
\hline & & & & & & Vehicle Tab & $u_{m k}$ \\
\hline \multirow{3}{*}{ MAN1 } & \multirow{3}{*}{304} & \multirow{3}{*}{266} & \multirow{3}{*}{3} & \multirow{3}{*}{1623} & \multirow{3}{*}{3} & VEH1 & $20[\mathrm{t}]$ \\
\hline & & & & & & VEH2 & 30 \\
\hline & & & & & & VEH3 & $30[\mathrm{~b}]$ \\
\hline \multirow{3}{*}{ MAN2 } & \multirow{3}{*}{22} & \multirow{3}{*}{412} & \multirow{3}{*}{5} & \multirow{3}{*}{1512} & \multirow{3}{*}{3} & VEH4 & $30[\mathrm{t}]$ \\
\hline & & & & & & VEH5 & 20 \\
\hline & & & & & & VEH6 & $20[b]$ \\
\hline
\end{tabular}


Table 8. Warehouse information of P01.

\begin{tabular}{|c|c|c|c|c|c|c|c|}
\hline \multirow{2}{*}{$\begin{array}{c}\text { Warehouse } \\
\text { Tab }\end{array}$} & \multirow{2}{*}{ X Coordinate } & \multirow{2}{*}{ Y Coordinate } & \multirow{2}{*}{$o_{p}$} & \multicolumn{2}{|c|}{ Material 1} & \multicolumn{2}{|c|}{ Material 2} \\
\hline & & & & Tab & Demand & Tab & Demand \\
\hline STO1 & 306 & 299 & 10 & MAT1 & 10 & MAT2 & $10[\mathrm{t}]$ \\
\hline STO2 & 387 & 84 & 6 & MAT3 & 6 & MAT4 & 6 \\
\hline STO3 & 411 & 488 & 1 & MAT5 & 1 & MAT6 & 1 \\
\hline STO4 & 352 & 210 & 10 & MAT7 & 10 & MAT8 & 10 \\
\hline STO5 & 197 & 252 & 2 & MAT9 & 2 & MAT10 & 2 \\
\hline STO6 & 91 & 378 & 8 & MAT11 & 8 & MAT12 & 8 \\
\hline STO7 & 306 & 65 & 1 & MAT13 & 1 & MAT14 & 1 \\
\hline STO8 & 43 & 19 & 9 & MAT15 & 9 & MAT16 & 9 \\
\hline STO9 & 175 & 415 & 10 & MAT17 & 10 & MAT18 & 10 \\
\hline STO10 & 426 & 103 & 4 & MAT19 & 4 & MAT20 & $4[\mathrm{~b}]$ \\
\hline
\end{tabular}

Then, the best solution of P01 solved by the HCDBAVNS is shown in Tables 9-11 and Figure 8 which reflect the following characteristics.

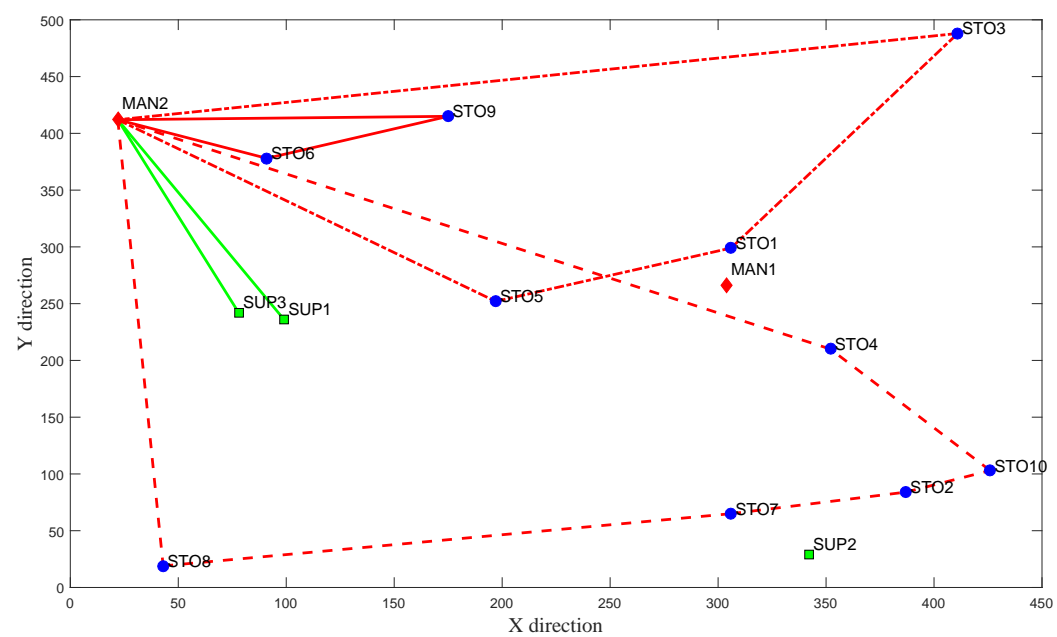

Figure 8. The schematic diagram of optimal solutions of P01 by HCDBAVNS.

Table 9. Warehouses served by suppliers in the optimal solution of P01 by HCDBAVNS.

\begin{tabular}{|c|c|c|c|c|}
\hline Item & Set Information & $\begin{array}{l}\text { Supply Quantity } \\
\text { of Material } 1\end{array}$ & $\begin{array}{l}\text { Supply Quantity } \\
\text { of Material } 2\end{array}$ & Material Cost \\
\hline \multirow{2}{*}{ The Material of Warehouses Served by Suppliers } & $\begin{array}{l}\text { SUP1: MAT3, } \\
\text { MAT11, MAT13, } \\
\text { MAT7, MAT 5, } \\
\text { MAT16, MAT18, } \\
\text { MAT17, MAT4, } \\
\text { MAT9 }\end{array}$ & 38 & 25 & 69,026 \\
\hline & $\begin{array}{l}\text { SUP3: MAT6, } \\
\text { MAT19, MAT2, } \\
\text { MAT1, MAT8, } \\
\text { MAT12, MAT15, } \\
\text { MAT10, MAT20, } \\
\text { MAT14 }\end{array}$ & 23 & 36 & 62,377 \\
\hline Total cost & & & & 131,403 \\
\hline
\end{tabular}


Table 10. The transportation from manufacturers to warehouses in the optimal solution of P01 by HCDBAVNS.

\begin{tabular}{|c|c|c|c|c|c|}
\hline Item & $\begin{array}{c}\text { Route } \\
\text { Information }\end{array}$ & Used Capacity & Processing Cost & Route Distance & $\begin{array}{c}\text { Transportation } \\
\text { Cost }\end{array}$ \\
\hline \multirow[t]{3}{*}{$\begin{array}{l}\text { The transportation } \\
\text { from manufacturers } \\
\text { to warehouses }\end{array}$} & $\begin{array}{c}\text { VEH4: MAN2-> } \\
\text { STO8-> } \\
\text { STO7-> } \\
\text { STO2- }-> \\
\text { STO10-> } \\
\text { STO4-> MAN2 }\end{array}$ & 30 & 45,360 & 1301 & 6505 \\
\hline & $\begin{array}{c}\text { VEH5: MAN2-> } \\
\text { STO5-> } \\
\text { STO1-> } \\
\text { STO3-> MAN2 }\end{array}$ & 13 & 19,656 & 967 & 4835 \\
\hline & $\begin{array}{c}\text { VEH6: MAN2 }-> \\
\text { STO9- }> \\
\text { STO6-> MAN2 }\end{array}$ & 18 & 27,216 & 320 & 1600 \\
\hline Total cost & & & 92,232 & & 12,940 \\
\hline
\end{tabular}

Table 11. The transportation from suppliers to manufacturers in the optimal solution of P01 by HCDBAVNS.

\begin{tabular}{cccc}
\hline \multicolumn{1}{c}{ Item } & Route Information & Route Distance & Transportation Cost \\
\hline $\begin{array}{l}\text { The transportation from } \\
\text { suppliers to manufacturers }\end{array}$ & SUP1- > MAN2 & 384 & 3840 \\
\cline { 2 - 4 } & SUP3- > MAN2 & 356 & 4984 \\
\hline \multicolumn{1}{c}{ Total cost } & & 8824 \\
\hline
\end{tabular}

1. The materials (i.e., MAT1, MAT2, .., MAT10) corresponding to the products needed by all warehouses are supplied by SUP1 and SUP3 without any omission. For the SUP1, the supply quantity of material 1 is 38 , and the supply quantity of material 2 is 25 , both of which have not exceeded their maximum supply quantities (38 and 26). Similarly, for the SUP3, the supply quantity of material 1 is 23 , and the supply quantity of material 2 is 36 , both of which have not exceeded their maximum supply quantities (24 and 36) either. It is worth noting that SUP2 is not selected in this best solution because the materials of SUP1 and SUP3 are cheaper than SUP2 and the material supply quantities of SUP1 and SUP3 have met the demand of all warehouses. In addition, SUP2 is further away from the MAN2 and MAN1 than SUP1 and SUP3.

2. All the products are made by MAN2 and delivered by three vehicles of MAN2. The actual loads of VEH4 are 30,13, and 18, respectively, all of which have not exceeded their maximum loading capacities (30,20, and 20). MAN1 is not selected for processing and delivery. Because the unit processing cost of MAN2 is cheaper than that of MAN1, and the position of MAN2 is closer to the SUP1 and SUP3 than MAN2.

This best solution satisfies the material supply constraint and maximum loading capacity constraint of VRPCSC, that is, it satisfies Formulas (9) and (10), so it is a feasible solution. Thus, HCDBAVNS can effectively solve VRPCSC.

\subsubsection{Experiment 2}

In order to assess the effectiveness HCDBAVNS, this experiment makes a comparison among HCDBAVNS without DCIS (denoted as HDBAVNS), VNS, Particle Swarm Optimization [30] with VNS (denoted as PSOVNS) and HCDBAVNS. This experiment selects 20 instances which have no known optimal solutions. The paper makes some assumptions to get a lower bound for each instance. 
Assuming that the purchase cost of materials can be calculated by the lowest price of materials of all suppliers in the Formula (1), and the lowest purchase cost of materials can be calculated as follows:

$$
\mathrm{Z}_{\mathrm{PUR}}^{\prime}=\sum_{p \in S P} \sum_{l \in S L} o^{\prime}{ }_{p l} \min _{s}\left\{c_{s l}\right\}
$$

Secondly, in Formula (2), assuming that maximum supply quantities of all suppliers are set to the maximal value of $e_{s l}$, and the unit delivery costs and distances are a set value between suppliers and manufacturers, then the lowest delivery cost of suppliers' vehicles are shown as follows:

$$
\mathrm{Z}_{\mathrm{STM}}^{\prime}=2 \times\left(\left[\sum_{p \in S P} \sum_{l \in S L} o_{p l}^{\prime} / \max \left(e_{s l}\right)\right]\right) \times \min _{s, m}\left\{d_{s m}\right\} \times \min _{s}\left\{b_{s}\right\}
$$

Thirdly, assuming the processing cost of materials can be calculated by the lowest processing price of all manufacturers in the Formula (3), and the lowest processing cost can be calculated by Formula (30).

$$
\mathrm{Z}_{\mathrm{PRO}}^{\prime}=\sum_{p \in S P} o_{p} \times \min \left\{c_{m}^{\prime}\right\}
$$

Lastly, assuming that maximum loading capacities of all manufacturers' vehicles are set to the maximal value of $u_{m k}$, and the unit delivery costs and distances are set the lowest value between manufacturers and warehouses, then the lowest delivery cost of manufacturers' vehicles are shown as follows:

$$
\begin{aligned}
\mathrm{Z}^{\prime}{ }_{\mathrm{MTS}} & =2 \times\left(\left[\sum_{p \in S P} o_{p} / \max _{m, k}\left(u_{m k}\right)\right]\right) \times \min \left\{d^{\prime}{ }_{m p}\right\} \times \min \left\{b^{\prime}{ }_{m k}\right\} \\
& +\left(P-\left\lceil\sum_{p \in S P} o_{p} / \max _{m, k}\left(u_{m k}\right)\right]\right) \times \min \left\{d^{\prime}{ }_{p p^{\prime}}\right\} \times \min \left\{b^{\prime}{ }_{m k}\right\}
\end{aligned}
$$

From Formula (1) to Formula (5), a lower bound $S \_L$ for each instance is obtained, denoded as Formula (32).

$$
S_{-} L=Z_{\text {PUR }}^{\prime}+Z_{\text {STM }}^{\prime}+Z_{\text {PRO }}^{\prime}+Z_{\text {MTS }}^{\prime}
$$

Then, the optimization rate $O P$ is calculated as Formula (33) which asses the quality of the solutions of the algorithm. The experiment results are shown in Tables 12 and 13 and Figure 9 .

$$
O P=\frac{\text { Best solution }-S \_L}{S \_L} \times 100 \%
$$

It can be seen from Tables 12 and 13 that: when time consumption of all the algorithms are close, all the best solutions, average solutions, and worst solutions of 20 instances solved by HCDBAVNS are not worse than those solved by VNS and PSOVNS. On the other hand, there are seven and nine instances of HCDBAVNS obviously better than HDBAVNS in both the best solutions and average solutions, accounting for $35 \%$ and $45 \%$ of the total instances, respectively. Then, although DCIS made the optimization capacity of HCDBAVNS not increase significantly (all the examples were less than $1 \%$ ), it made HCDBAVNS more steady. 
Table 12. Result of HCDBAVNS and HDBAVNS.

\begin{tabular}{|c|c|c|c|c|c|c|c|c|c|c|c|c|c|}
\hline \multirow{2}{*}{\multicolumn{2}{|c|}{ Instance }} & \multirow[b]{2}{*}{ MIT } & \multirow[b]{2}{*}{$S \_L$} & \multicolumn{5}{|c|}{ VNS } & \multicolumn{5}{|c|}{ PSOVNS } \\
\hline & & & & $\begin{array}{c}\text { Best } \\
\text { Solution }\end{array}$ & $\begin{array}{l}\text { Average } \\
\text { Solution }\end{array}$ & $\begin{array}{c}\text { Worst } \\
\text { solution }\end{array}$ & $O P(\%)$ & Time & $\begin{array}{c}\text { Best } \\
\text { Solution }\end{array}$ & $\begin{array}{l}\text { Average } \\
\text { Solution }\end{array}$ & $\begin{array}{c}\text { Worst } \\
\text { Solution }\end{array}$ & $O P(\%)$ & Time \\
\hline \multirow{5}{*}{ G1 } & P01 & 200 & 227,607 & 245,399 & $245,399.0$ & 245,399 & 7.82 & 4.3 & 245,399 & $245,399.0$ & 245,399 & 7.82 & 4.5 \\
\hline & P02 & 200 & 211,615 & 238,905 & $238,905.0$ & 238,905 & 12.90 & 4.5 & 238,905 & $238,905.0$ & 238,905 & 12.90 & 4.3 \\
\hline & P03 & 200 & 259,559 & 286,191 & $286,191.0$ & 286,191 & 10.26 & 4.3 & 286,191 & $286,191.0$ & 286,191 & 10.26 & 4.2 \\
\hline & P04 & 200 & 213,048 & 240,149 & $240,149.0$ & 240,149 & 12.72 & 4.2 & 240,149 & $240,149.0$ & 240,149 & 12.72 & 4.1 \\
\hline & P05 & 200 & 241,592 & 269,959 & $269,959.0$ & 269,959 & 11.74 & 3.9 & 269,959 & $269,959.0$ & 269,959 & 11.74 & 3.8 \\
\hline \multirow{5}{*}{ G2 } & P06 & 2000 & 401,972 & 450,664 & $453,527.2$ & 455,186 & 12.11 & 45.9 & 452,185 & $454,078.6$ & 455,367 & 12.49 & 46.5 \\
\hline & P07 & 2000 & 482,338 & 562,425 & $564,518.4$ & 566,501 & 16.60 & 23.3 & 563,563 & $564,828.2$ & 566,140 & 16.84 & 23.5 \\
\hline & P08 & 2000 & 353,804 & 411,177 & $411,947.6$ & 412,274 & 16.22 & 47.9 & 411,177 & $411,963.0$ & 412,859 & 16.22 & 47.6 \\
\hline & P09 & 2000 & 462,224 & 539,301 & $540,791.6$ & 541,875 & 16.68 & 18.8 & 539,351 & $541,266.4$ & 542,524 & 16.69 & 19.2 \\
\hline & P10 & 2000 & 357,230 & 401,208 & $403,241.8$ & 404,232 & 12.31 & 41.8 & 403,287 & $403,459.4$ & 403,829 & 12.89 & 41.3 \\
\hline \multirow{5}{*}{ G3 } & P11 & 1000 & 342,420 & 379,602 & $379,602.0$ & 379,602 & 10.86 & 14.1 & 379,602 & $379,602.0$ & 379,602 & 10.86 & 14.9 \\
\hline & P12 & 1000 & 423,011 & 468,178 & $469,600.8$ & 470,907 & 10.68 & 15.3 & 468,906 & $470,519.6$ & 470,971 & 10.85 & 15.6 \\
\hline & P13 & 1000 & 341,952 & 371,543 & $371,543.0$ & 371,543 & 8.65 & 19.5 & 371,543 & $371,543.0$ & 371,543 & 8.65 & 19.1 \\
\hline & P14 & 1000 & 370,158 & 406,929 & $406,929.0$ & 406,929 & 9.93 & 21.5 & 406,929 & $406,929.0$ & 406,929 & 9.93 & 21.2 \\
\hline & P15 & 1000 & 532,112 & 588,222 & $588,222.0$ & 588,222 & 10.54 & 15.6 & 588,222 & $588,222.0$ & 588,222 & 10.54 & 15.7 \\
\hline \multirow{5}{*}{ G4 } & P16 & 3000 & 807,715 & 938,095 & $940,699.0$ & 942,193 & 16.14 & 59.2 & 940,460 & $941,739.4$ & 942,517 & 16.43 & 59.5 \\
\hline & P17 & 3000 & 958,872 & $1,132,475$ & $1,136,530.4$ & $11,373,88$ & 18.10 & 50.1 & $1,133,556$ & $1,139,009.8$ & $1,143,398$ & 18.22 & 50.6 \\
\hline & P18 & 3000 & 826,146 & 893,681 & $894,655.0$ & 896,728 & 8.17 & 61.2 & 893,700 & $895,485.4$ & 898,046 & 8.18 & 61.5 \\
\hline & P19 & 3000 & 625,755 & 675,812 & $677,138.0$ & 678,534 & 8.00 & 82.7 & 676,342 & $677,294.8$ & 678,405 & 8.08 & 82.3 \\
\hline & P20 & 3000 & 642,355 & 696,039 & $696,477.6$ & 696,969 & 8.36 & 85.9 & 696,039 & $696,684.2$ & 697,473 & 8.36 & 86.3 \\
\hline
\end{tabular}

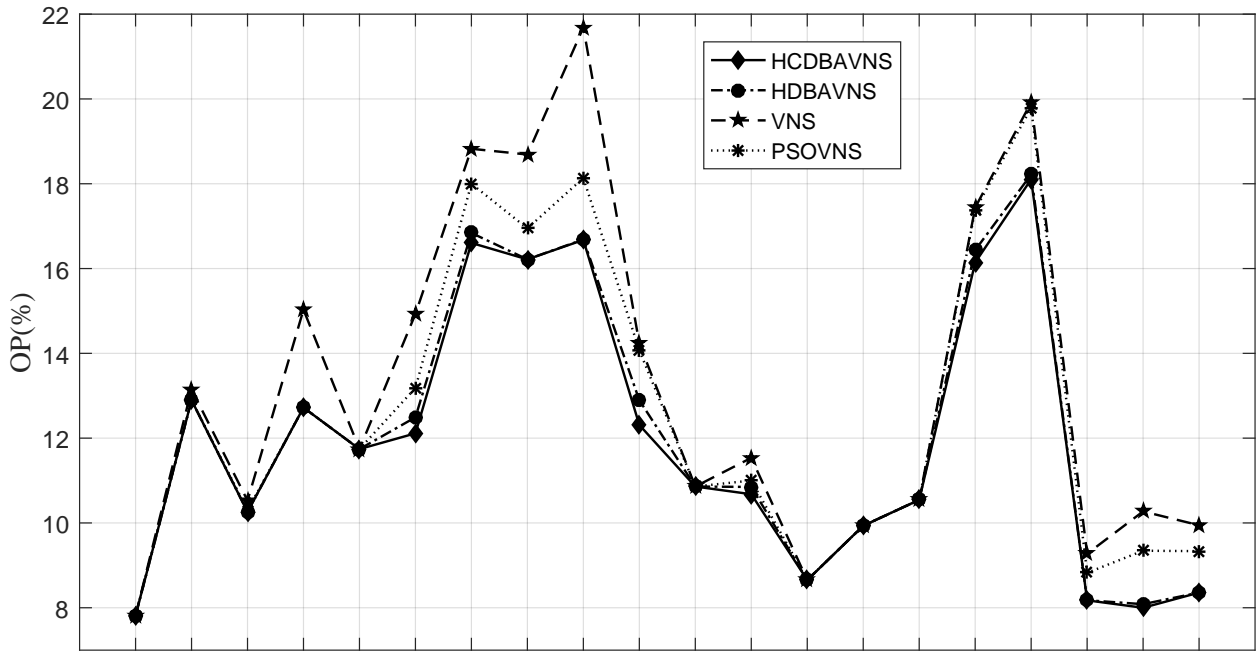

P01 P02 P03 P04 P05 P06 P07 P08 P09 P10 P11 P12 P13 P14 P15 P16 P17 P18 P19 P20 Instances

Figure 9. OP of HCDBAVNS, HDBAVNS, VNS and APSOVNS. 
Table 13. Result of VNS and APSOVNS.

\begin{tabular}{|c|c|c|c|c|c|c|c|c|c|c|c|c|c|}
\hline \multirow{2}{*}{\multicolumn{2}{|c|}{ Instance }} & \multirow[b]{2}{*}{ MIT } & \multirow[b]{2}{*}{$S \_L$} & \multicolumn{5}{|c|}{ VNS } & \multicolumn{5}{|c|}{ PSOVNS } \\
\hline & & & & $\begin{array}{c}\text { Best } \\
\text { Solution }\end{array}$ & $\begin{array}{l}\text { Average } \\
\text { Solution }\end{array}$ & $\begin{array}{c}\text { Worst } \\
\text { solution }\end{array}$ & $O P(\%)$ & Time & $\begin{array}{c}\text { Best } \\
\text { Solution }\end{array}$ & $\begin{array}{l}\text { Average } \\
\text { Solution }\end{array}$ & $\begin{array}{c}\text { Worst } \\
\text { Solution }\end{array}$ & $O P(\%)$ & Time \\
\hline \multirow{5}{*}{ G1 } & P01 & 200 & 227,607 & 245,399 & $247,606.8$ & 250,222 & 7.82 & 4.9 & 245,399 & $245,850.2$ & 246,527 & 7.82 & 4.5 \\
\hline & P02 & 200 & 211,615 & 239,446 & $241,699.0$ & 243,061 & 13.15 & 4.1 & 238,905 & $239,255.2$ & 239,807 & 12.90 & 4.4 \\
\hline & P03 & 200 & 259,559 & 286,882 & $287,921.6$ & 289,545 & 10.53 & 4.6 & 286,291 & $286,291.0$ & 286,291 & 10.30 & 4.3 \\
\hline & P04 & 200 & 213,048 & 245,069 & $248,848.2$ & 250,150 & 15.03 & 3.9 & 240,149 & $242,305.0$ & 245,069 & 12.72 & 4.3 \\
\hline & P05 & 200 & 241,592 & 269,959 & $270,079.4$ & 270,329 & 11.74 & 4.1 & 269,959 & $269,959.0$ & 269,959 & 11.74 & 3.8 \\
\hline \multirow{5}{*}{ G2 } & P06 & 2000 & 401,972 & 461,985 & $465,777.2$ & 473,112 & 14.93 & 46.1 & 454,971 & $456,304.6$ & 457,961 & 13.18 & 46.5 \\
\hline & P07 & 2000 & 482,338 & 573,135 & $577,617.6$ & 581,841 & 18.82 & 23.6 & 569,162 & $569,866.8$ & 570,764 & 18.00 & 24.1 \\
\hline & P08 & 2000 & 353,804 & 419,927 & $422,849.0$ & 425,984 & 18.69 & 29.5 & 413,760 & $413,848.0$ & 413,931 & 16.95 & 49.9 \\
\hline & P09 & 2000 & 462,224 & 562,461 & $563,011.0$ & 564,653 & 21.69 & 20.5 & 546,047 & $550,210.4$ & 552,288 & 18.13 & 20.3 \\
\hline & P10 & 2000 & 357,230 & 408,072 & $414,620.6$ & 419,073 & 14.23 & 39.5 & 407,489 & $407,716.2$ & 407,829 & 14.07 & 40.9 \\
\hline \multirow{5}{*}{ G3 } & P11 & 1000 & 342,420 & 379,602 & $379,903.6$ & 380,142 & 10.86 & 15.6 & 379,602 & $379,602.0$ & 379,602 & 10.86 & 14.8 \\
\hline & P12 & 1000 & 423,011 & 471,805 & $474,410.4$ & 475,715 & 11.53 & 15.8 & 469,544 & $464,248.7$ & 471,044 & 11.00 & 15.4 \\
\hline & P13 & 1000 & 341,952 & 371,543 & $371,655.4$ & 371,907 & 8.65 & 19.2 & 371,543 & $371,543.0$ & 371,543 & 8.65 & 19.3 \\
\hline & P14 & 1000 & 370,158 & 406,929 & $406,936.2$ & 406,947 & 9.93 & 20.6 & 406,929 & $406,929.0$ & 406,929 & 9.93 & 21.2 \\
\hline & P15 & 1000 & 532,112 & 588,222 & $588,222.0$ & 588,222 & 10.54 & 15.8 & 588,222 & $588,222.0$ & 588,222 & 10.54 & 15.8 \\
\hline \multirow{5}{*}{ G4 } & P16 & 3000 & 807,715 & 948,560 & $954,319.4$ & 957,402 & 17.44 & 54.7 & 948,136 & $948,838.6$ & 949,841 & 17.38 & 56.3 \\
\hline & P17 & 3000 & 958,872 & $1,149,885$ & $1,154,544.0$ & $1,156,343$ & 19.92 & 49.5 & $1,148,604$ & $1,150,104.4$ & $1,152,467$ & 19.79 & 61.5 \\
\hline & P18 & 3000 & 826,146 & 902,756 & $904,639.6$ & 907,400 & 9.27 & 63.2 & 899,041 & $899,651.4$ & 900,260 & 8.82 & 62.2 \\
\hline & P19 & 3000 & 625,755 & 690,032 & $692,122.6$ & 694,282 & 10.27 & 86.4 & 684,229 & $685,327.8$ & 686,814 & 9.34 & 88.4 \\
\hline & P20 & 3000 & 642,355 & 706,239 & $707,694.0$ & 709,278 & 9.95 & 90.4 & 702,318 & $704,458.8$ & 705,547 & 9.33 & 92.4 \\
\hline
\end{tabular}

In Figure 9, it can be sees that HCDBAVNS has a higher possibility of finding a better solution than VNS. Especially, the OP of HCDBAVNS, which is $4 \%$ less than that of VNS in P09. In addition, HDBAVNS is also better than PSOVNS. It proves that BA has better global optimization ability than PSO.

Further, the paired two-sample mean analysis method in the $t$-Test is used to test whether the three algorithms are significantly different. Supposing that the significance level is 0.05 and mean deviation is 0 , The experimental results are shown in Table 14. In the $t$-Test, $p>0.05$ indicates no significant difference; $0.01<p<0.05$ indicates a significant difference; $p<0.01$ indicates an extreme significant difference.

Table 14. Student's t-test.

\begin{tabular}{cccc}
\hline \multirow{2}{*}{ Tab } & \multirow{2}{*}{-Test } & \multicolumn{2}{c}{$p$ Value } \\
\cline { 3 - 4 } & & Best Solution & Average Solution \\
\hline W1 & HCDBAVNS vs. HDBAVNS & 0.01149 & $0.01514[\mathrm{t}]$ \\
W2 & HCDBAVNS vs. VNS & 0.00034 & 0.00005 \\
W3 & HDBAVNS vs. VNS & 0.0005 & 0.00005 \\
W4 & HDBAVNS vs. PSOVNS & 0.00148 & $0.00610[\mathrm{~b}]$ \\
\hline
\end{tabular}

In Table 14, it can be seen from W1 test that the $p$ values of the best solution and average solution are 0.01149 and 0.01514 (both less than 0.05). In other words, both the best solution and average solution of HCDBAVNS show significant differences to HDBAVNS.

In addition, compared with VNS, HDBAVNS, and HCDBAVNS have shown extreme significant differences. Furthermore, HDBAVNS shows a significant difference to PSOVNS. This also proves that HCDBAVNS finally exhibits strong optimization capability and stability. 


\section{Conclusions}

Based on the vehicle routing problem in the three-echelon supply chain, this paper proposes a VRPCSC model and constructs HCDBAVNS to solve it. Two sets of experiments were conducted, which showed the effectiveness of the proposed algorithm in solving the VRPCSC. In the future, more complex factors will be considered to establish a more comprehensive supply chain model, such as the manufacturer's maximum processing volume and the manufacturer's processing time. Accordingly, we can use Taguchi or RSM to tune the parameters and compare the influence of different methods of parameter values. In addtion, we can apply the algorithm to solve actual examples and compare the actual scheme, so as to judge the quality of the solutions obtained by the algorithm.

Author Contributions: Writing—original draft preparation, Y.Q.; Writing—review and editing, Y.C. All authors have read and agreed to the published version of the manuscript.

Funding: This work is partially supported by the Science and Technology Program of Tianhe District, Guangzhou under grant No. 2018CX005, the Key Project in Higher Education of Guangdong Province, China under grant No. 2020ZDZX3030 and the Science and Technology Foundation of Guangdong Province under grant No. 2021A0101180005.

Institutional Review Board Statement: Not applicable.

Informed Consent Statement: Not applicable.

Data Availability Statement: The data presented in this study are available on request from the corresponding author.

Acknowledgments: The authors would like to thank Peng Hou for his contributions to the algorithm development and all authors' help of comments which makes the paper more readable.

Conflicts of Interest: The authors declare no conflict of interest.

\section{References}

1. Karimi, B.; Ghare Hassanlu, M.; Niknamfar, A.H. An integrated production-distribution planning with a routing problem and transportation cost discount in a supply chain. Assem. Autom. 2019, 39, 783-802. [CrossRef]

2. Saif-Eddine, A.S.; El-Beheiry, M.M.; El-Kharbotly, A.K. An improved genetic algorithm for optimizing total supply chain cost in inventory location routing problem. Ain Shams Eng. J. 2019, 10, 63-76. [CrossRef]

3. Apte, U.M.; Viswanathan, S. Effective cross docking for improving distribution efficiencies. Int. J. Logist. Res. Appl. 2000, 3, 291-302. [CrossRef]

4. Setak, M.; Habibi, M.; Karimi, H.; Abedzadeh, M. A time-dependent vehicle routing problem in multigraph with FIFO property. J. Manuf. Syst. 2015, 35, 37-45. [CrossRef]

5. Govindan, K.; Jafarian, A.; Nourbakhsh, V. Designing a sustainable supply chain network integrated with vehicle routing: A comparison of hybrid swarm intelligence metaheuristics. Comput. Oper. Res. 2019, 110, 220-235. [CrossRef]

6. Qi, Y.; Cai, Y.; Cai, H.; Yang, L.; Yeboah, Y. Two-Level Bat Algorithm with Variable Neighborhood Search for Capacitated Vehicle Routing Problem in Supply Chain. Acta Electron. Sin. 2019, 47, 1434-1442.

7. Wen, M.; Larsen, J.; Clausen, J.; Cordeau, J.F.; Laporte, G. Vehicle routing with cross-docking. J. Oper. Res. Soc. 2009, 60, 1708-1718. [CrossRef]

8. Rohrer, M. Simulation and cross docking. In Proceedings of the Winter Simulation Conference Proceedings, Arlington, VA, USA, 3-6 December 1995; pp. 846-849.

9. Yu, W.; Egbelub, P.J. Scheduling of inbound and outbound trucks in cross docking systems with temporary storage. Eur. J. Oper. Res. 2008, 184, 377-396. [CrossRef]

10. Lim, A.; Ma, H.; Miao, Z. Truck dock assignment problem with operational time constraint within crossdocks. Eur. J. Oper. Res. 2009, 192, 105-115.

11. Boysen, N. Truck scheduling at zero-inventory cross docking terminals. Comput. Oper. Res. 2010, 37, 32-41. [CrossRef]

12. Ahmadizar, F.; Zeynivand, M.; Arkat, J. Two-level vehicle routing with cross-docking in a three-echelon supply chain: A genetic algorithm approach. Appl. Math. Model. 2015, 39, 7065-7081. [CrossRef]

13. Zuluaga, J.P.S.; Thiell, M.; Perales, R.C. Reverse cross-docking. Omega 2017, 66, 48-57. [CrossRef]

14. Liu, S. On the integrated production, inventory, and distribution routing problem. IIE Trans. 2006, 38, 955-970.

15. Qiu, Y.; Qiao, J.; Pardalos, P.M. A branch-and-price algorithm for production routing problems with carbon cap-and-trade. Omega 2017, 68, 49-61. [CrossRef]

16. Kumar, R.S.; Kondapaneni, K.; Dixit, V.; Goswami, A.; Thakur, L.S.; Tiwari, M.K. Multi-objective modeling of production and pollution routing problem with time window. Comput. Ind. Eng. 2016, 99, 29-40. [CrossRef] 
17. Darvish, M.; Archetti, C.; Coelho, L.C. Trade-offs between environmental and economic performance in production and inventory-routing problems. Int. J. Prod. Econ. 2019, 217, 269-280. [CrossRef]

18. Wang, Z.; Ren, X.; Ji, Z.; Huang, W.; Wu, T. A novel bio-heuristic computing algorithm to solve the capacitated vehicle routing problem based on Adleman Lipton model. Biosystems 2019, 184, 103997. [CrossRef]

19. Liu, J.; Wan, J.; Jia, D.; Zeng, B.; Li, D.; Hsu, C.H.; Chen, H. High-Efficiency Urban Traffic Management in Context-Aware Computing and 5G Communication. IEEE Commun. Mag. 2017, 55, 34-40.

20. Qi, Y.; Cai, Y.; Cai, H.; Huang, H. Discrete bat algorithm for vehicle routing problem with time window. Acta Electron. Sin. 2018, 46, 672-679. [CrossRef]

21. Qi, Y.; Hou, P.; Yang, L.; Yang, G. Simultaneous optimisation of cable connection schemes and capacity for offshore wind farms via a modified bat algorithm. Appl. Sci. 2019, 9, 265. [CrossRef]

22. Qi, Y.; Cai, Y.; Cai, H.; Tang, Y.; Lv, W. Chaotic hybrid bat algorithm for travelling salesman problem. Acta Electron. Sin. 2016, 44, 2543-2547. [CrossRef]

23. Yang, X.S. A new metaheuristic bat-inspired algorithm. In Nicso 2010: Nature Inspired Cooperative Strategies for Optimization; Gonzalez, J.R., Pelta, D.A., Cruz, C., Terrazas, G., Krasnogor, N., Eds.; Springer: Berlin, Germany, 2010; Volume 284, pp. 65-74.

24. Osaba, E.; Yang, X.S.; Diaz, F.; Lopez-Garcia, P.; Carballedo, R. An improved discrete bat algorithm for symmetric and asymmetric Traveling Salesman Problems. Eng. Appl. Artif. Intell. 2016, 48, 59-71. [CrossRef]

25. El-Semary, A.M.; Azim, M.M.A.; Diab, H. SPCBC: A Secure Parallel Cipher Block Chaining Mode of Operation based on logistic Chaotic Map. KSII Trans. Internet Inf. Syst. 2017, 11, 3608-3628. [CrossRef]

26. Cai, Y.; Qi, Y.; Cai, H.; Huang, H.; Chen, H. Chaotic discrete bat algorithm for capacitated vehicle routing problem. Int. J. Auton. Adapt. Commun. Syst. 2019, 12, 91-108. [CrossRef]

27. Gao, S. Solving traveling salesman problem by chaos ant colony optimization algorithm. Syst. Eng. Theory Pract. 2005, 25, 100-104. [CrossRef]

28. Alvarez, A.; Munari, P.; Morabito, R. Iterated local search and simulated annealing algorithms for the inventory routing problem. Int. Trans. Oper. Res. 2018, 25, 1785-1809. [CrossRef]

29. Hiermann, G.; Puchinger, J.; Ropke, S.; Hartl, R.F. The electric fleet size and mix vehicle routing problem with time windows and recharging stations. Eur. J. Oper. Res. 2016, 252, 995-1018. [CrossRef]

30. Zhan, Z.H.; Zhang, J.; Li, Y.; Chung, H.S.H. Adaptive Particle Swarm Optimization. IEEE Trans. Syst. Man Cybern. Part B-Cybern. 2009, 39, 1362-1381. [CrossRef] 